\title{
Three-Dimensional $\mathrm{Zn}_{0.5} \mathrm{Cd}_{0.5} \mathrm{~S} /$ Reduced Graphene Oxide Hybrid Aerogel: Facile Synthesis and the Visible-Light-Driven Photocatalytic Property for Reduction of Cr(VI) in Water
}

\author{
Wei Xiao, Wenjie Zhou, Yanhua Zhang, Liangliang Tian, Hongdong Liu, and Yong Pu \\ Research Institute for New Materials Technology, Chongqing University of Arts and Sciences, Yongchuan, Chongqing 402160, China \\ Correspondence should be addressed to Wei Xiao; showame@aliyun.com and Yanhua Zhang; zyhcoco@163.com
}

Received 21 April 2016; Revised 4 August 2016; Accepted 11 August 2016

Academic Editor: Takuya Tsuzuki

Copyright (C) 2016 Wei Xiao et al. This is an open access article distributed under the Creative Commons Attribution License, which permits unrestricted use, distribution, and reproduction in any medium, provided the original work is properly cited.

\begin{abstract}
A series of three-dimensional $\mathrm{Zn}_{x} \mathrm{Cd}_{1-x} \mathrm{~S}$ /reduced graphene oxide $\left(\mathrm{Zn}_{x} \mathrm{Cd}_{1-x} \mathrm{~S} / \mathrm{RGO}\right)$ hybrid aerogels was successfully synthesized based on a one-pot hydrothermal approach, which were subsequently used as visible-light-driven photocatalysts for photoreduction of $\mathrm{Cr}(\mathrm{VI})$ in water. Over $95 \%$ of $\mathrm{Cr}(\mathrm{VI})$ was photoreduced by $\mathrm{Zn}_{0.5} \mathrm{Cd}_{0.5} \mathrm{~S} / \mathrm{RGO}$ aerogel material within $140 \mathrm{~min}$, and such photocatalytic performance was superior to that of other $\mathrm{Zn}_{x} \mathrm{Cd}_{1-x} \mathrm{~S} / \mathrm{RGO}$ aerogel materials $(x \neq 0.5)$ and bare $\mathrm{Zn}_{0.5} \mathrm{Cd}_{0.5} \mathrm{~S}$. It was assumed that the enhanced photocatalytic activity of $\mathrm{Zn}_{0.5} \mathrm{Cd}_{0.5} \mathrm{~S} / \mathrm{RGO}$ aerogel was attributed to its high specific surface area and the preferable synergetic catalytic effect between $\mathrm{Zn}_{0.5} \mathrm{Cd}_{0.5} \mathrm{~S}$ and RGO. Besides, $\mathrm{Zn}_{0.5} \mathrm{Cd}_{0.5} \mathrm{~S} / \mathrm{RGO}$ aerogel materials were robust and durable enough so that they could be reused several times with merely limited loss of photocatalytic activity. The chemical composition, phase, structure, and morphology of $\mathrm{Zn}_{0.5} \mathrm{Cd}_{0.5} \mathrm{~S} / \mathrm{RGO}$ aerogel material were carefully examined by a number of techniques like XRD, SEM, TEM, BET, Raman characterizations, and so on. It was found that $\mathrm{Zn}_{0.5} \mathrm{Cd}_{0.5} \mathrm{~S} / \mathrm{RGO}$ aerogel possessed hierarchically porous architecture with the specific surface area as high as $260.8 \mathrm{~m}^{2} \mathrm{~g}^{-1}$. The $\mathrm{Zn}_{0.5} \mathrm{Cd}_{0.5} \mathrm{~S}$ component incorporated in $\mathrm{Zn}_{0.5} \mathrm{Cd}_{0.5} \mathrm{~S} / \mathrm{RGO}$ aerogel existed in the form of solid solution nanoparticles, which were uniformly distributed in the RGO matrix.
\end{abstract}

\section{Introduction}

Water pollution is becoming more and more serious all over the word and threatening the survival and development of human beings. Among the water pollutants, heavy metal ions especially hexavalent chromium $\mathrm{Cr}(\mathrm{VI})$ are acutely hazardous because of the extreme toxicity and high mobility in aqueous environment $[1,2]$. Several techniques such as membrane separation, adsorption, ion exchange, and photocatalytic reduction have been utilized to treat $\mathrm{Cr}(\mathrm{VI})$ contamination [1-5]. Compared with other methods, heterogeneous photocatalytic reduction using nanostructured semiconductor photocatalysts has been considered as a promising way to remove $\mathrm{Cr}(\mathrm{VI})$, particularly when it is present at low concentrations $[2,6]$. However, most of the traditional photocatalysts like $\mathrm{TiO}_{2}$ and $\mathrm{ZnO}$ are only active in UV light region, which contributes to about $4 \%$ of the solar energy, thus severely limiting their practical applications $[2,6,7]$. Considering the large proportion (around 43\%) of the solar energy from visible light, it is highly desirable to explore novel visible-light-driven photocatalysts to achieve high-performance photocatalytic reactions for environmental remediation and protection.

Recently, metal sulfides have attracted tremendous attention due to their prominent physicochemical properties. Among them, CdS is regarded as an excellent visible-lightresponsive photocatalyst candidate on account of the narrow band $\left(E_{g}=2.4 \mathrm{eV}\right)$ as well as its appropriate conduction band edge (more negative than the $\mathrm{H}_{2} \mathrm{O} / \mathrm{H}_{2}$ redox potential) [8-10]. However, CdS often suffers from photocorrosion and instability in photocatalytic systems $[9,10]$. To overcome the disadvantages, lots of strategies have been proposed including the preparation of multicomponent chalcogenide solid solutions [9-16]. For example, by introducing $\mathrm{ZnS}$ into $\mathrm{CdS}$, various semiconductor $\mathrm{Zn}_{x} \mathrm{Cd}_{1-x} \mathrm{~S}$ solid solutions with different structures and morphologies were produced, which not only possessed improved photocorrosion resistance but also exhibited efficient visible-light-responsive photocatalytic 
activities for degradation of organic dyes [9-13, 15, 16], whereas direct use of nanosized $\mathrm{Zn}_{x} \mathrm{Cd}_{1-x} \mathrm{~S}$ matters in photocatalytic reactions readily intrigues aggregation behavior owing to the small size and brings about fast recombination of photogenerated electrons and holes [9-11]. Both of the two negative factors could severely lower the photocatalytic abilities. Therefore, immobilization, dispersion, or hybridization of $\mathrm{Zn}_{x} \mathrm{Cd}_{1-x} \mathrm{~S}$ solid solutions with diverse solid substrates like semiconductor metal oxide, graphitic carbon nitride, carbon nanotubes, and other carbonaceous species has been explored $[9,12,17-19]$.

Graphene has fascinated the materials research community since its discovery due to the unique properties. In particular, its huge specific surface area makes it an ideal support for depositing or growing guest substances, and, meanwhile, its exceptional electrical conductivity makes it an excellent electron acceptor and transporter [20-25]. Consequently, a large variety of semiconductor photocatalysts were hybridized with reduced graphene oxide (RGO) for photocatalytic applications, leading to the formation of the corresponding RGO-containing composites $[8,9,13$, $20,21,23-25]$. It has been proven that RGO incorporated in the hybrid photocatalysts facilitated the charge transfer and suppressed the recombination of charge carries during photocatalytic reactions thus giving rise to their enhanced photocatalytic performances $[8,20,21,23,24]$. However, even so, some drawbacks for the synthesis of RGO-based hybrid photocatalysts still exist. For instance, most of the reported works were focused on the fabrication of two-dimensional (2D) RGO-based composites; that is, photocatalytic active species were just anchored on the surface of RGO sheets. In such circumstances, serious restacking or agglomeration of 2D RGO sheets would inevitably take place during drying and usage as a result of the van der Waals force, which dramatically reduced the accessible surface area of the hybrid photocatalysts and limited the transport of mass and photoexcited electrons to a large extent [26]. To address these issues, self-assembly of 2D RGO sheets into macroscopic three-dimensional (3D) architecture seems to be a feasible choice since it is capable of effectively circumventing the restacking of RGO sheets, providing hierarchically porous structure with large specific surface area, and contributing to the fast electron transport [26]. Accordingly, some functional nanoparticles have been successfully introduced, embedded, or captured in the 3D RGO networks, yielding novel RGObased aerogel materials [8, 20, 26-41]. Previously, $\mathrm{SnO}_{2} / \mathrm{RGO}$ and $\mathrm{TiO}_{2} /$ RGO hydrogels were generated via hydrothermal treatment of aqueous dispersions of graphene oxide (GO) in the presence of $\mathrm{SnO}_{2}$ and $\mathrm{TiO}_{2}$ nanoparticles, respectively $[26,27]$. Besides, by mixing aqueous suspension of GO with the solution of suitable metal salt and reducing agent, a homogeneous mixture was produced. Then, it was subjected to hydrothermal treatment, resulting in the formation of metal nanoparticle (including $\mathrm{Au}, \mathrm{Ag}, \mathrm{Pt}$, and $\mathrm{Ni}$ )/RGO hydrogels [28-33]. Other metal oxide (including $\mathrm{Fe}_{3} \mathrm{O}_{4}$, $\mathrm{Fe}_{2} \mathrm{O}_{3}, \mathrm{MnO}_{2}, \mathrm{CeO}_{2}, \mathrm{Co}_{3} \mathrm{O}_{4}$, and $\left.\mathrm{VO}_{2}\right) / \mathrm{RGO}$ and metal sulfide (including $\mathrm{MoS}_{2}, \mathrm{CoS}_{2}, \mathrm{ZnS}$, and NiS)/RGO hydrogels were similarly hydrothermally developed as well [20, 34-41]. These hydrogels were easily converted into the corresponding aerogels after a vacuum freeze-drying process, which displayed extraordinary performances in plenty of challenging fields like catalysis, sensing, adsorption, supercapacitors, lithium storage, and so on [8, 20, 26-41]. Motivated by the remarkable properties of RGO-based aerogel materials and their facile synthetic strategy, herein, we report a series of $3 \mathrm{D} \mathrm{Zn}_{x} \mathrm{Cd}_{1-x} \mathrm{~S} / \mathrm{RGO}$ hybrid aerogels, which were fabricated based on the one-pot hydrothermal method employing $\mathrm{Zn}(\mathrm{OAc})_{2}$ and $\mathrm{Cd}(\mathrm{OAc})_{2}$ as metal precursors and thiourea as sulfur source. In contrast with other $\mathrm{Zn}_{x} \mathrm{Cd}_{1-x} \mathrm{~S} / \mathrm{RGO}$ hybrid aerogels $(x \neq 0.5)$, RGO aerogel, and bare $\mathrm{Zn}_{0.5} \mathrm{Cd}_{0.5} \mathrm{~S}$ solid solution, $\mathrm{Zn}_{0.5} \mathrm{Cd}_{0.5} \mathrm{~S} / \mathrm{RGO}$ hybrid aerogel gave the best performance toward the photocatalytic reduction of $\mathrm{Cr}(\mathrm{VI})$ in water under visible light and such hybrid photocatalyst was robust, durable, and photocorrosion resistant enough so that it was able to be reused many times with limited loss of photocatalytic activity, exhibiting outstanding practical application potential.

\section{Materials and Methods}

2.1. Materials and Reagents. GO sheets were provided by Nanjing JCNANO Technology Co., Ltd. (Nanjing, China). $\mathrm{Zn}(\mathrm{OAc})_{2} \cdot 2 \mathrm{H}_{2} \mathrm{O}, \mathrm{Cd}(\mathrm{OAc})_{2} \cdot 2 \mathrm{H}_{2} \mathrm{O}$, and thiourea $\mathrm{CS}\left(\mathrm{NH}_{2}\right)_{2}$ were bought by Sinopharm Chemical Reagent Co., Ltd. $\mathrm{K}_{2} \mathrm{Cr}_{2} \mathrm{O}_{7}$ was purchased from Sigma-Aldrich Co., Ltd., and employed as the $\mathrm{Cr}(\mathrm{VI})$ source for the photocatalytic experiments. All chemicals were guaranteed reagents and used as received. All aqueous solutions and dispersions were prepared with Milli-Q water (resistivity, $18.2 \mathrm{M} \Omega \mathrm{cm}$ ).

2.2. Synthesis of $3 D \mathrm{Zn}_{x} C d_{1-x} \mathrm{~S} / \mathrm{RGO}$ Hybrid Aerogels. 3D $\mathrm{Zn}_{x} \mathrm{Cd}_{1-x} \mathrm{~S} / \mathrm{RGO}$ hybrid aerogels were synthesized based on a one-pot hydrothermal process. In a typical procedure, $\mathrm{Zn}(\mathrm{OAc})_{2} \cdot 2 \mathrm{H}_{2} \mathrm{O}$ and $\mathrm{Cd}(\mathrm{OAc})_{2} \cdot 2 \mathrm{H}_{2} \mathrm{O}$ with fixed total amount of $2 \mathrm{mmol}$ but different molar ratios were dissolved in $1 \mathrm{~mL}$ water. This $1 \mathrm{~mL}$ of solution and another $1 \mathrm{~mL}$ of aqueous solution containing $8 \mathrm{mmol}$ of thiourea were sequentially added to $18 \mathrm{~mL}$ of aqueous GO suspension containing $40 \mathrm{mg}$ GO sheets under vigorous stirring. The resulting homogeneous mixture was then transferred into a stainless-steel autoclave with the capacity of $50 \mathrm{~mL}$ and sealed to heat at $180^{\circ} \mathrm{C}$ for $12 \mathrm{~h}$. After the hydrothermal reaction, the autoclave was naturally cooled to room temperature and a cylindrical $\mathrm{Zn}_{x} \mathrm{Cd}_{1-x} \mathrm{~S} / \mathrm{RGO}$ hydrogel was located at its bottom, which was then taken out, washed with water, and immersed in abundant fresh water for 3 days to remove the impurities. Subsequently, the hydrogel was freeze-dried under vacuum to obtain the corresponding $\mathrm{Zn}_{x} \mathrm{Cd}_{1-x} \mathrm{~S} / \mathrm{RGO}$ hybrid aerogel. It is noted that the $x$ value is the molar ratio of $\mathrm{Zn}$ precursor to the two kinds of metal precursors, and when it equals $0,0.2$, $0.4,0.5,0.6,0.8$, and 1 , the corresponding hybrid aerogels are labeled as CdS/RGO, $\mathrm{Zn}_{0.2} \mathrm{Cd}_{0.8} \mathrm{~S} / \mathrm{RGO}, \mathrm{Zn}_{0.4} \mathrm{Cd}_{0.6} \mathrm{~S} / \mathrm{RGO}$, $\mathrm{Zn}_{0.5} \mathrm{Cd}_{0.5} \mathrm{~S} / \mathrm{RGO}, \mathrm{Zn}_{0.6} \mathrm{Cd}_{0.6} \mathrm{~S} / \mathrm{RGO}, \mathrm{Zn}_{0.8} \mathrm{Cd}_{0.2} \mathrm{~S} / \mathrm{RGO}$, and $\mathrm{ZnS} / \mathrm{RGO}$, respectively. For comparison, RGO aerogel was likewise fabricated in the absence of any metal precursor and $\mathrm{Zn}_{0.5} \mathrm{Cd}_{0.5} \mathrm{~S}$ solid solution was also prepared according to the synthetic conditions of $\mathrm{Zn}_{0.5} \mathrm{Cd}_{0.5} \mathrm{~S} / \mathrm{RGO}$ hydrogel but without addition of GO sheets. 
2.3. Photocatalytic Reduction of $\mathrm{Cr}(\mathrm{VI})$ under Visible Light. Photocatalytic reduction of $\mathrm{Cr}(\mathrm{VI})$ in water using the currently developed $\mathrm{Zn}_{0.5} \mathrm{Cd}_{0.5} \mathrm{~S} / \mathrm{RGO}$ hybrid aerogel as visiblelight-driven photocatalyst was tested by employing a photoreactor (JOYN-GHX-A, Shanghai JOYN Electronic Co., Ltd.), which was equipped with a xenon lamp $(500 \mathrm{~W})$ for visible light irradiation. Typically, $50 \mathrm{mg}$ of $\mathrm{Zn}_{0.5} \mathrm{Cd}_{0.5} \mathrm{~S} / \mathrm{RGO}$ aerogel material was dispersed into $50 \mathrm{~mL}$ of aqueous solution of $\mathrm{K}_{2} \mathrm{Cr}_{2} \mathrm{O}_{7}\left(20 \mathrm{mg} \mathrm{L}^{-1}\right)$. The resulting suspension was put into the photocatalytic setup and exposed to visible light illumination under continuous stirring with a constant horizontal distance $(10 \mathrm{~cm})$ between the xenon lamp and reaction mixture. At $20 \mathrm{~min}$ intervals, $3 \mathrm{~mL}$ of aliquots was extracted from the reaction system and centrifuged to get rid of the photocatalyst, while the upper clear solutions were analyzed on an UV-vis spectrophotometer. The variations of the concentrations of $\mathrm{Cr}(\mathrm{VI})$ in reaction mixture with irradiation time were monitored by recording the absorption band changes of the upper clear solutions located at $370 \mathrm{~nm}$. For comparison, the photoreduction of $\mathrm{Cr}(\mathrm{VI})$ catalyzed by other $\mathrm{Zn}_{x} \mathrm{Cd}_{1-x} \mathrm{~S} / \mathrm{RGO}$ hybrid aerogels materials $(x \neq 0.5)$, $\mathrm{Zn}_{0.5} \mathrm{Cd}_{0.5} \mathrm{~S}$ solid solution, and RGO aerogel material as well as the photoreduction of $\mathrm{Cr}(\mathrm{VI})$ without any photocatalyst was conducted under the identical experimental conditions. Moreover, repetitive photoreduction of $\mathrm{Cr}(\mathrm{VI})$ under visible light using $\mathrm{Zn}_{0.5} \mathrm{Cd}_{0.5} \mathrm{~S} / \mathrm{RGO}$ aerogel material as photocatalyst was evaluated as well. After the first run of photocatalytic reaction, the suspension was centrifuged to separate the photocatalyst, which was once again dispersed in a fresh solution of $\mathrm{K}_{2} \mathrm{Cr}_{2} \mathrm{O}_{7}$ to form a new reaction mixture for the next round of photoreduction.

2.4. Characterizations. UV-vis spectra were measured on a Hitachi U-3900 spectrophotometer in the transmission mode with pure water as reference standard. Raman spectra were collected on a Horiba Scientific Raman spectrometer using $532 \mathrm{~nm}$ laser line as the excitation source. X-ray photoelectron spectra (XPS) were obtained from a VG ESCALAB MARK II instrument with a monochromatic and focused $\mathrm{Mg}$ $\mathrm{K} \alpha$ radiation source $(h v=1253.6 \mathrm{eV})$ operating at an energy of $15 \mathrm{kV} / 300 \mathrm{~W}$ under a residual pressure of $\sim 2 \times 10^{-9}$ mbar. Atomic adsorption spectroscopy was analyzed on a Shimadzu AA-680 atomic absorption spectrophotometer fixed with deuterium background corrector using air-acetylene flame. Field emission scanning electron microscopy (FESEM) observations were carried out by using a Hitachi S4800 instrument working at an acceleration voltage of $3 \mathrm{kV}$, and all of the specimens were directly observed owing to their excellent conductivity. Transmission electron microscopy (TEM) inspections were performed on a Tecnai G2 F20 instrument operating at an acceleration voltage of $200 \mathrm{kV}$. Energy dispersive X-ray spectra (EDS) and two-dimensional element mapping of materials were detected on Oxford Energy Dispersive X-ray equipment working at an acceleration of $20 \mathrm{kV}$. Nitrogen adsorption-desorption isotherm was made at $77 \mathrm{~K}$ employing a Micromeritics ASAP 2020 equipment; the specific surface area was estimated through the BrunauerEmmett-Teller (BET) model; and the pore size distribution

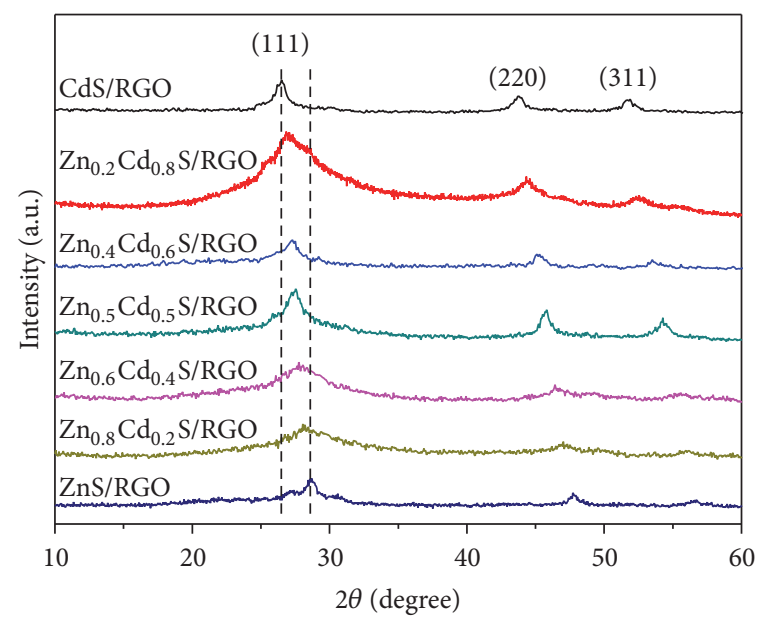

FIGURE 1: XRD patterns of the currently developed $\mathrm{Zn}_{x} \mathrm{Cd}_{1-x} \mathrm{~S} / \mathrm{RGO}$ hybrid aerogels with different $x$ values.

was analyzed by the Barrett-Joyner-Halenda (BJH) method. Thermogravimetric analysis (TGA) was conducted using a Netzsch TG 209F1 apparatus at a heating rate of $10^{\circ} \mathrm{C} \mathrm{min}^{-1}$ in air flow. X-ray diffraction (XRD) patterns were acquired on a Bruker D8 Advance diffractometer with a $\mathrm{CuK} \alpha(\lambda=$ $0.15418 \mathrm{~nm}$ ) radiation source.

\section{Results and Discussion}

3.1. Composition, Structure, and Morphology of $\mathrm{Zn}_{0.5} \mathrm{Cd} d_{0.5} \mathrm{~S} / \mathrm{RGO}$ Hybrid Aerogel. To understand the crystal phase and structural information of the $\mathrm{Zn}_{x} \mathrm{Cd}_{1-x} \mathrm{~S} / \mathrm{RGO}$ hybrid aerogel materials, XRD technique was applied. As presented in Figure 1, three main diffraction peaks of CdS/RGO aerogel centered at $2 \theta=26.6^{\circ}, 43.9^{\circ}$, and $52.0^{\circ}$ are well indexed to (111), (220), and (311) crystal planes of cubic CdS (JCPDS number 65-2887), respectively. Likewise, the XRD patterns of the other $\mathrm{Zn}_{x} \mathrm{Cd}_{1-x} \mathrm{~S} / \mathrm{RGO}$ aerogels also show three diffraction peaks analogous to those for CdS/RGO aerogel, which are indicative of cubic zinc blende structure of all the $\mathrm{Zn}_{x} \mathrm{Cd}_{1-x} \mathrm{~S}$ components incorporated in these samples $[9,19]$. Notably, as the $x$ value goes up, namely, as the $\mathrm{Zn}$ content increases, gradual shift of the diffraction peaks to larger angles takes place, suggesting that the produced $\mathrm{Zn}_{x} \mathrm{Cd}_{1-x} \mathrm{~S}$ components comprise of the corresponding solid solutions rather than a simple mixture of $\mathrm{ZnS}$ with CdS $[9,19,42]$. The generation of $\mathrm{Zn}_{x} \mathrm{Cd}_{1-x} \mathrm{~S}$ solid solutions means that $\mathrm{Zn}^{2+}$ has incorporated into the lattice of CdS or entered its interstitial sites by virtue of the smaller ionic radius of $\mathrm{Zn}^{2+}(0.74 \AA)$ than that of $\mathrm{Cd}^{2+}(0.97 \AA)$ $[9,19,42]$. Nevertheless, the characteristic broad peak of RGO $\left(2 \theta=25^{\circ}\right.$, shown in Figure S1 in Supplementary Material available online at http://dx.doi.org/10.1155/2016/6201546) does not appear in the XRD patterns of all $\mathrm{Zn}_{x} \mathrm{Cd}_{1-x} \mathrm{~S} / \mathrm{RGO}$ aerogels, whose absence is likely ascribed to the weak diffraction intensity $[8,9,43]$.

Figure 2 is the Raman spectra of GO sheets and $\mathrm{Zn}_{0.5} \mathrm{Cd}_{0.5} \mathrm{~S} / \mathrm{RGO}$ hybrid aerogel material. Obviously, both 


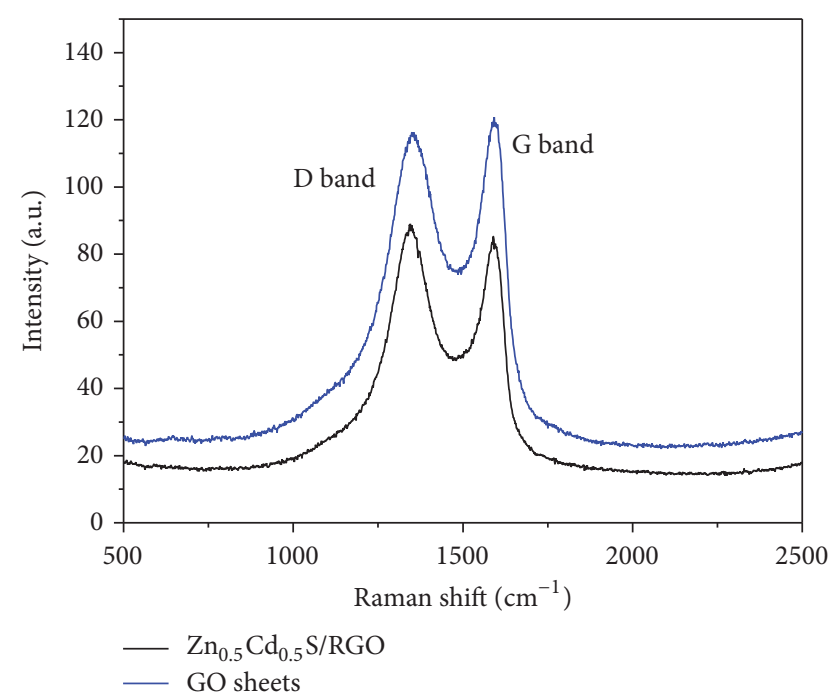

FIgURE 2: Raman spectra of GO sheets (blue curve) and $\mathrm{Zn}_{0.5} \mathrm{Cd}_{0.5} \mathrm{~S} / \mathrm{RGO}$ hybrid aerogel material (black curve).

curves show two prominent bands at $1350 \mathrm{~cm}^{-1}$ (D band) and $1590 \mathrm{~cm}^{-1}$ ( $\mathrm{G}$ band), demonstrating the existence of carbon species $[8,21,31]$. $\mathrm{D}$ band is commonly related to the structural disruption and defects of the symmetrical hexagonal graphitic lattice, while $G$ band is attributed to the first-order scattering of $E_{2 g}$ phonons within $\mathrm{sp}^{2}$-bonded carbon materials $[8,20,21]$. The peak intensity ratio of $\mathrm{D}$ to $\mathrm{G}$ band, $I_{\mathrm{D}} / I_{\mathrm{G}}$, can be used to estimate the disorder level and defect degree of the $\mathrm{sp}^{2}$-bonded carbon domains of graphite materials $[20,21]$. As can be directly calculated from the peak intensity displayed in Figure 2, the values of $I_{\mathrm{D}} / I_{\mathrm{G}}$ for $\mathrm{GO}$ sheets and $\mathrm{Zn}_{0.5} \mathrm{Cd}_{0.5} \mathrm{~S} / \mathrm{RGO}$ hybrid aerogel material are 0.85 and 1.05 , respectively. The former is much lower than the latter, manifesting that the GO sheets underwent a significant removal of oxygen-containing groups and were indeed reduced to RGO during the hydrothermal process $[20,31,40]$.

XPS spectroscopy is a useful tool for discovering the surface state of composite materials. Figure 3(a) is the highresolution XPS spectrum of GO sheets for $\mathrm{C} 1$ s region. Figures 3(b)-3(e) present a set of high-resolution XPS spectra of $\mathrm{Zn}_{0.5} \mathrm{Cd}_{0.5} \mathrm{~S} / \mathrm{RGO}$ aerogel for $\mathrm{C} 1 \mathrm{~s}, \mathrm{Zn} 2 \mathrm{p}, \mathrm{Cd} 3 \mathrm{~d}$, and $\mathrm{S}$ $2 \mathrm{p}$ regions, respectively, and the detected signals verify the presence of the four elements in this product. Both of the $\mathrm{C}$ 1s spectra can be resolved into four Gaussian peaks. The dominant peak at $284.6 \mathrm{eV}$ is assigned to the aromatic $\mathrm{sp}^{2}$ $\mathrm{C}=\mathrm{C}$ bonding in graphitic structure, while the other three peaks centered around $286.6 \mathrm{eV}, 287.5 \mathrm{eV}$, and $289.3 \mathrm{eV}$ result from the oxygen-containing functional groups like $\mathrm{C}-\mathrm{OH}$, $\mathrm{C}-\mathrm{O}-\mathrm{C}$, and $\mathrm{HO}-\mathrm{C}=\mathrm{O}$, respectively $[8,9,22]$. Most of the carbon atoms in $\mathrm{GO}$ sheets and $\mathrm{Zn}_{0.5} \mathrm{Cd}_{0.5} \mathrm{~S} / \mathrm{RGO}$ aerogel are bonded in the form of $\mathrm{sp}^{2}$. However, in comparison with the $\mathrm{C}$ 1s spectrum of GO sheets, the peak intensities for the oxygen-containing functional groups in the $\mathrm{C}$ 1s spectrum of $\mathrm{Zn}_{0.5} \mathrm{Cd}_{0.5} \mathrm{~S} / \mathrm{RGO}$ aerogel remarkably decrease, implying the abundant loss of these oxygen-containing functional groups during the hydrothermal reaction $[8,9,20,22]$. Namely, GO sheets have been sufficiently reduced to RGO component in such process [8, 9, 20, 22]. Moreover, XPS $\mathrm{Zn} 2 \mathrm{p}$ and $\mathrm{Cd} 3 \mathrm{~d}$ spectra disclose representative curves for $\mathrm{Zn} 2 \mathrm{p}$ and $\mathrm{Cd} 3 \mathrm{~d}$ doublets with the binding energies (BE) of $1046.7 \mathrm{eV}$ for $\mathrm{Zn} 2 \mathrm{p}_{1 / 2}, 1022.8 \mathrm{eV}$ for $\mathrm{Zn} 2 \mathrm{p}_{3 / 2}, 411.7 \mathrm{eV}$ for $\mathrm{Cd} 3 \mathrm{~d}_{3 / 2}$, and $405.0 \mathrm{eV}$ for $\mathrm{Cd} 3 \mathrm{~d}_{5 / 2}$, respectively, which are in good agreement with the previously reported values for $\mathrm{Zn}_{x} \mathrm{Cd}_{1-x} \mathrm{~S}$ solid solution $[9,16,17]$. The BE splitting of $23.9 \mathrm{eV}$ for $\mathrm{Zn} 2 \mathrm{p}$ doublets and $6.7 \mathrm{eV}$ for $\mathrm{Cd} 3 \mathrm{~d}$ doublets verifies that the chemical states of elements $\mathrm{Zn}$ and $\mathrm{Cd}$ within the $\mathrm{Zn}_{0.5} \mathrm{Cd}_{0.5} \mathrm{~S} / \mathrm{RGO}$ hybrid aerogel are both +2 valence $[9,17]$. That is, they exist in the form of $\mathrm{Zn}^{2+}$ and $\mathrm{Cd}^{2+}$, respectively $[9,17]$. XPS S 2 p spectrum gives a single peak located at $162.1 \mathrm{eV}$, demonstrating the existence of element $\mathrm{S}$ in the form $\mathrm{S}^{2-}$, which should arise from $\mathrm{Zn}-\mathrm{S}$ and $\mathrm{Cd}-$ $S$ bonds [9, 15-17]. The content of RGO incorporated in $\mathrm{Zn}_{0.5} \mathrm{Cd}_{0.5} \mathrm{~S} / \mathrm{RGO}$ hybrid aerogel was determined by its TGA measurement from room temperature to $700^{\circ} \mathrm{C}$. As exhibited in Figure 4, the TGA profile shows a slight weight loss of $2.5 \%$ at below $200^{\circ} \mathrm{C}$, which should be owing to the physically and chemically adsorbed water molecules [44, 45]. Generally, a further increase of temperature from 200 to $600^{\circ} \mathrm{C}$ leads to the decomposition and complete burning of RGO within the sample to $\mathrm{CO}_{2}[44,45]$. Therefore, according to the weight loss profile of $\mathrm{Zn}_{0.5} \mathrm{Cd}_{0.5} \mathrm{~S} / \mathrm{RGO}$ hybrid aerogel material, the RGO content within it is calculated to be $46.9 \%$.

The as-prepared bulk $\mathrm{Zn}_{0.5} \mathrm{Cd}_{0.5} \mathrm{~S} / \mathrm{RGO}$ aerogel is monolithic and free-standing as shown in the inset of Figure 5(a). Its microscopic morphology and structure are carefully examined by FE-SEM and TEM observations. As can be clearly seen in the low-magnified FE-SEM image (Figure 5(a)), the $\mathrm{Zn}_{0.5} \mathrm{Cd}_{0.5} \mathrm{~S} / \mathrm{RGO}$ aerogel features a welldefined and interconnected porous RGO network with lots of continuous macropores on micrometer scale. The ultrathin, flexible, and crumpled RGO sheets can be identified by closer inspections, which meanwhile reveal considerable narrow mesopores and voids with irregular shape created by the their accumulation (Figures 5(b) and 5(c)), demonstrating the hierarchically porous architecture. Besides, the highmagnified FE-SEM images (Figures 5(b) and 5(c)) show that a great number of nanoparticles with the size of several tens of nanometers are evenly embedded in the 3D RGO framework, which should be the $\mathrm{Zn}_{0.5} \mathrm{Cd}_{0.5} \mathrm{~S}$ solid solution. In addition to the XPS analysis, the chemical composition of $\mathrm{Zn}_{0.5} \mathrm{Cd}_{0.5} \mathrm{~S} / \mathrm{RGO}$ aerogel is further validated by its EDS spectrum where elements $\mathrm{C}, \mathrm{Zn}, \mathrm{Cd}$, and $\mathrm{S}$ are available and the atomic ratio of $\mathrm{Zn}: \mathrm{Cd}: \mathrm{S}$ is quite close to $1: 1: 2$ (Figures 5(d) and 5(e)), commendably matching with the stoichiometric ratio of $\mathrm{Zn}_{0.5} \mathrm{Cd}_{0.5} \mathrm{~S}$ solid solution. Figures 5(f)-5(i) are EDS mapping images of elements $\mathrm{C}, \mathrm{Zn}, \mathrm{Cd}$, and $\mathrm{S}$ within $\mathrm{Zn}_{0.5} \mathrm{Cd}_{0.5} \mathrm{~S} / \mathrm{RGO}$ aerogel, respectively, which visualize their spatial distribution. Evidently, the uniform signals are full of the same detection zone, manifesting the homogeneity of all the four elements in this specimen. Figure $5(\mathrm{j})$ is a TEM image of $\mathrm{Zn}_{0.5} \mathrm{Cd}_{0.5} \mathrm{~S} / \mathrm{RGO}$ aerogel with low magnification, displaying that $\mathrm{Zn}_{0.5} \mathrm{Cd}_{0.5} \mathrm{~S}$ solid solution nanoparticles are uniformly and densely dispersed on the 


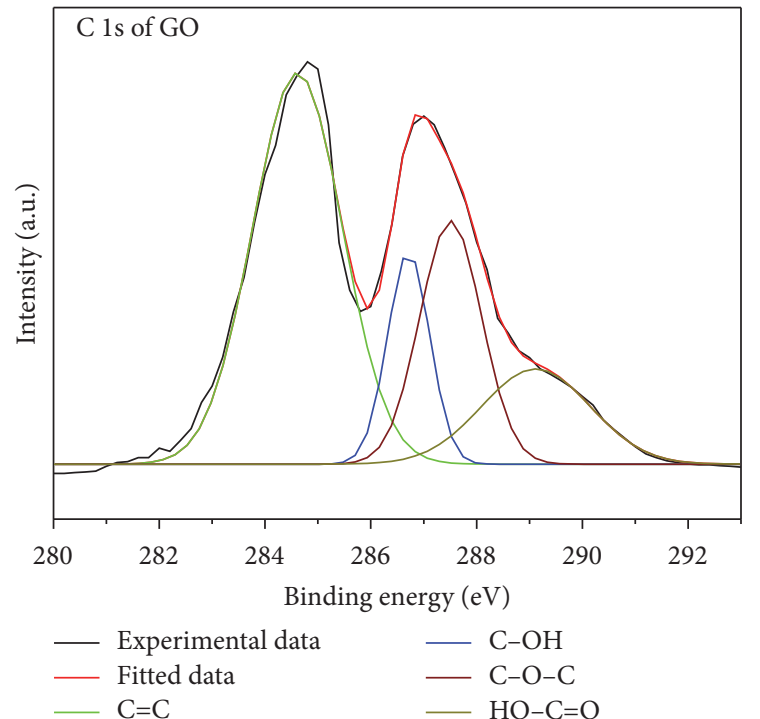

(a)

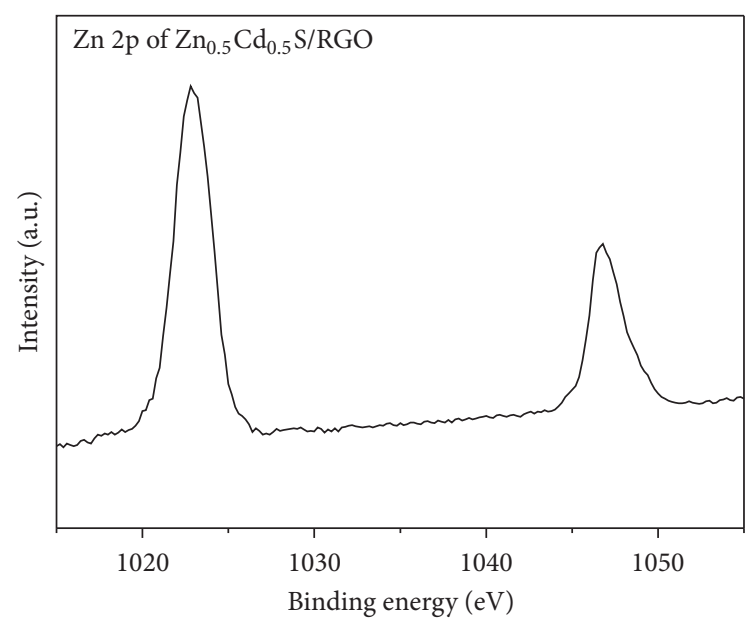

(c)

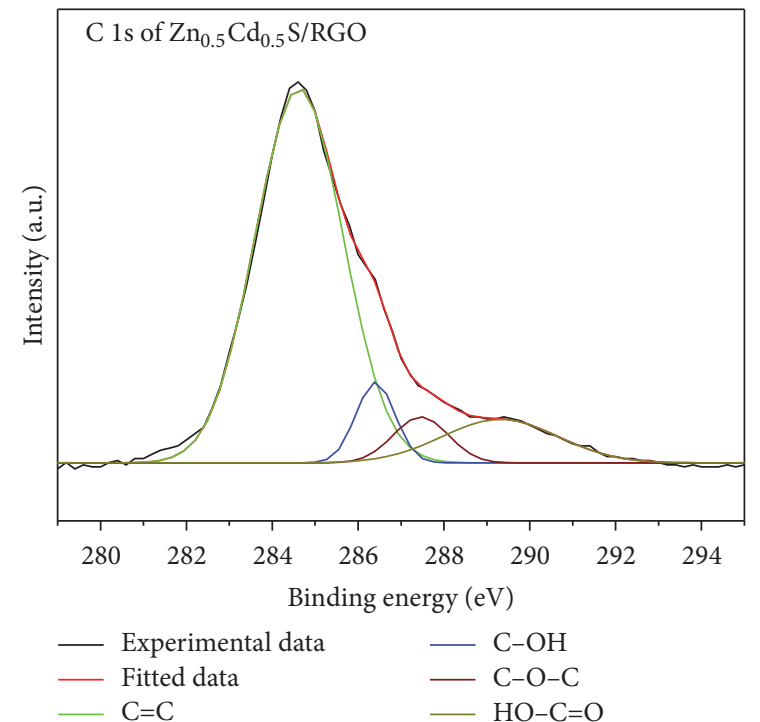

(b)

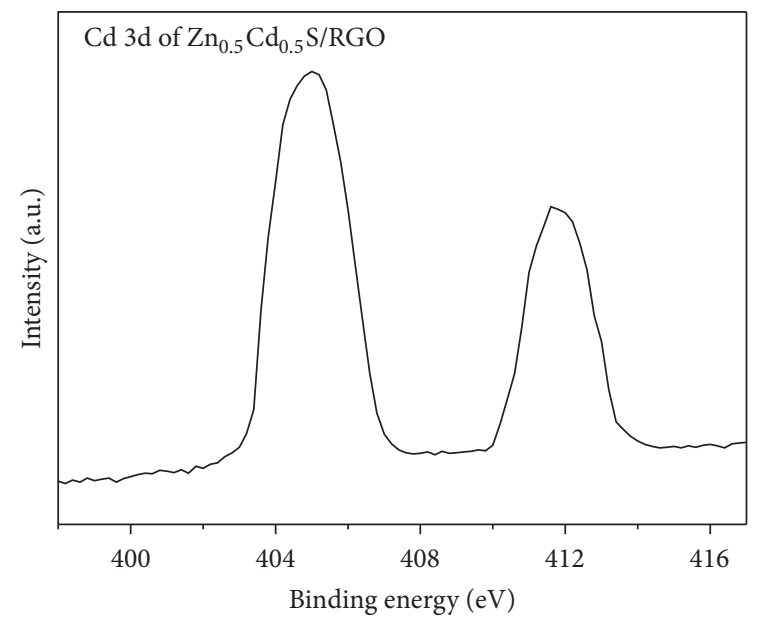

(d)

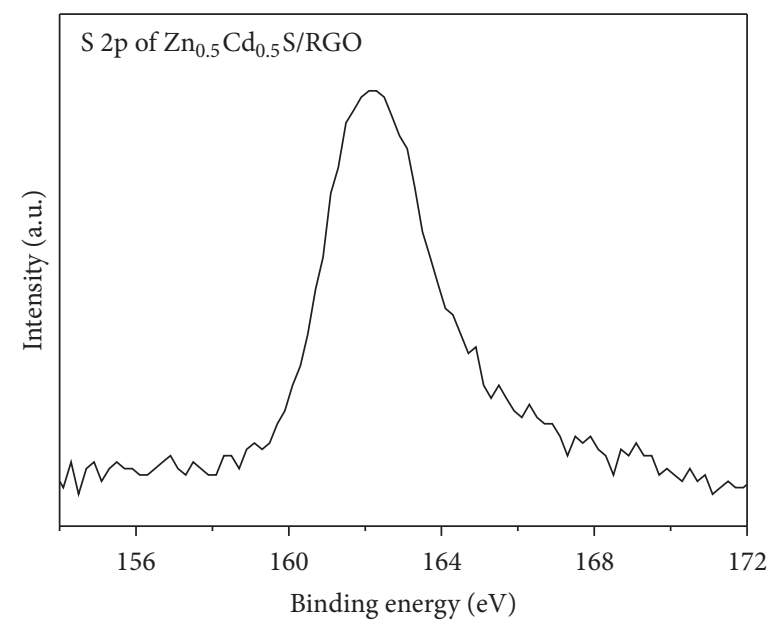

(e)

FIGURE 3: (a) High-resolution XPS spectrum of C 1s region of GO sheets. (b-e) High-resolution XPS spectra of $\mathrm{Zn}_{0.5} \mathrm{Cd}_{0.5} \mathrm{~S} / \mathrm{RGO}$ hybrid aerogel material for $\mathrm{C} 1 \mathrm{~s}, \mathrm{Zn} 2 \mathrm{p}$, Cd 3d, and S 2p regions, respectively. 


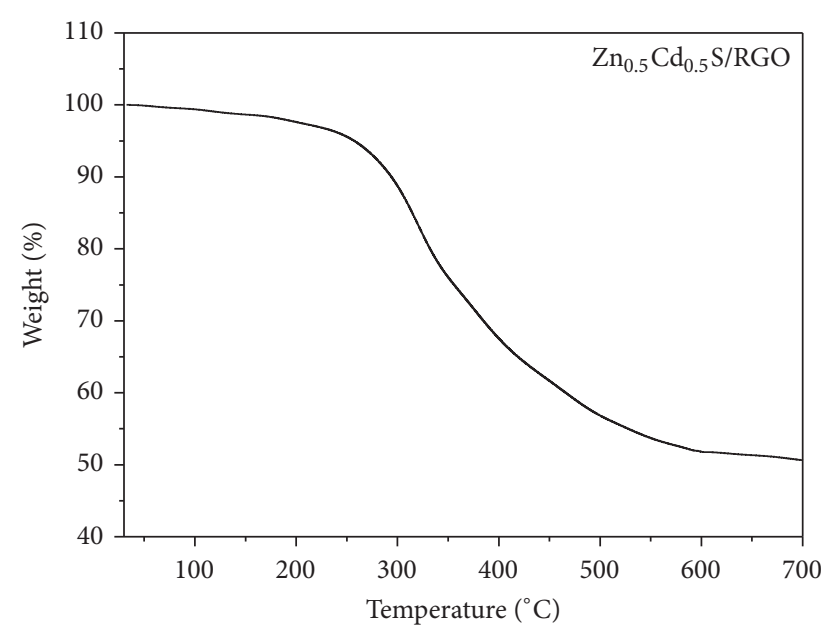

FIGURE 4: TGA profile of $\mathrm{Zn}_{0.5} \mathrm{Cd}_{0.5} \mathrm{~S} / \mathrm{RGO}$ hybrid aerogel material.

surface of RGO sheets. Such TEM observation result agrees well with the morphological characteristics revealed by FESEM examinations (Figures 5(b) and 5(c)). Interestingly, the $\mathrm{Zn}_{0.5} \mathrm{Cd}_{0.5} \mathrm{~S}$ solid solution nanoparticles observed in the FESEM images actually consist of smaller nanocrystals, which are merely several nanometers in diameter as revealed by the high-magnified TEM image (Figure 5(k)). Figure 5(l) presents a high-resolution TEM (HRTEM) image of an individual $\mathrm{Zn}_{0.5} \mathrm{Cd}_{0.5} \mathrm{~S}$ nanocrystal within $\mathrm{Zn}_{0.5} \mathrm{Cd}_{0.5} \mathrm{~S} / \mathrm{RGO}$ aerogel, where the lattice fringes are clearly visible, indicating the highly crystalline nature. The interplanar distance is calculated to be $0.31 \mathrm{~nm}$, which corresponds to the (111) plane of cubic zinc blende phase of $\mathrm{Zn}_{0.5} \mathrm{Cd}_{0.5} \mathrm{~S}$ solid solution $[9,16,43-45]$. From all these above data and results, it is inferred that the reduction of GO to RGO, the formation, growth, and crystallization of $\mathrm{Zn}_{0.5} \mathrm{Cd}_{0.5} \mathrm{~S} / \mathrm{RGO}$ solid solution nanoparticles, their deposition on RGO substrate, and the self-assembly of $2 \mathrm{D}$ RGO sheets to $3 \mathrm{D}$ porous structure through $\pi-\pi$ stacking interactions were almost synchronously accomplished, resulting in the hybridization of $\mathrm{Zn}_{0.5} \mathrm{Cd}_{0.5} \mathrm{~S}$ solid solution nanoparticles with $\mathrm{RGO}$ to form the $3 \mathrm{D} \mathrm{Zn}_{0.5} \mathrm{Cd}_{0.5} \mathrm{~S} / \mathrm{RGO}$ hybrid hydrogel [26]. Therefore, after it was freeze-dried under vacuum, the macroscopic 3D cylindrical shape was retained and the microscopic hierarchically porous architecture was generated, readily yielding the $3 \mathrm{D} \mathrm{Zn}_{0.5} \mathrm{Cd}_{0.5} \mathrm{~S} / \mathrm{RGO}$ hybrid aerogel material with unique structure and morphology.

The porous property of $\mathrm{Zn}_{0.5} \mathrm{Cd}_{0.5} \mathrm{~S} / \mathrm{RGO}$ aerogel was surveyed by BET measurement. Figure 6(a) depicts its typical nitrogen adsorption-desorption isotherm. According to the IUPAC nomenclature, the isotherm belongs to type IV with a $\mathrm{H} 4$ hysteresis loop at the relative pressure $\left(P / P_{0}\right)$ between 0.3 and 0.95 , which is associated with the capillary condensation occurring in mesopores, indicating the presence of narrow slit-shaped mesopores in the hybrid aerogel material [4648]. The corresponding pore size distribution data obtained from the adsorption branch of isotherm curve by the $\mathrm{BJH}$ method are shown in Figure 6(b), illustrating that the pore size mainly ranges from several to dozens of nanometers.
These BET results are quite consistent with the FE-SEM examinations (Figures 5(b) and 5(c)). Moreover, the specific surface area of $\mathrm{Zn}_{0.5} \mathrm{Cd}_{0.5} \mathrm{~S} / \mathrm{RGO}$ hybrid aerogel reaches up to $260.8 \mathrm{~m}^{2} \mathrm{~g}^{-1}$, which is much larger than that of RGO aerogel $\left(147.1 \mathrm{~m}^{2} \mathrm{~g}^{-1}\right)$ and $\mathrm{Zn}_{0.5} \mathrm{Cd}_{0.5} \mathrm{~S}$ solid solution $\left(66.4 \mathrm{~m}^{2} \mathrm{~g}^{-1}\right)$, implying that the generation and decoration of $\mathrm{Zn}_{0.5} \mathrm{Cd}_{0.5} \mathrm{~S}$ solid solution nanoparticles within 3D RGO matrix not only functionalize the final product (i.e., the $\mathrm{Zn}_{0.5} \mathrm{Cd}_{0.5} \mathrm{~S} / \mathrm{RGO}$ hybrid aerogel material) but also serve as the spacer to partially alleviate the agglomeration of RGO sheets. As such, the hierarchically porous architecture of $\mathrm{Zn}_{0.5} \mathrm{Cd}_{0.5} \mathrm{~S} / \mathrm{RGO}$ hybrid aerogel material with higher specific surface area can enlarge reaction space, offer numerous reactive sites, favor mass transport, and, hence, ensure its splendid photocatalytic property.

3.2. Photocatalytic Property of $Z n_{0.5} C d_{0.5} S / R G O$ Hybrid Aerogel Material. The photocatalytic activity of $\mathrm{Zn}_{0.5} \mathrm{Cd}_{0.5} \mathrm{~S} / \mathrm{RGO}$ hybrid aerogel material was evaluated by conducting the photoreduction of $\mathrm{Cr}(\mathrm{VI})$ in aqueous media under visible light irradiation. As control, the photocatalytic performances of $\mathrm{Zn}_{x} \mathrm{Cd}_{1-x}$ S hybrid aerogel materials $(x \neq 0.5), \mathrm{Zn}_{0.5} \mathrm{Cd}_{0.5} \mathrm{~S}$ solid solution, and RGO aerogel material were tested under the same conditions as well. The results are shown in Figure 6, where $C_{0}$ and $C$ are the initial concentration of $\mathrm{Cr}(\mathrm{VI})$ and its measured concentration at irradiation time $t$, respectively. Apparently, without any photocatalyst, the selfreduction of $\mathrm{Cr}(\mathrm{VI})$ could be neglected. For the currently developed $\mathrm{Zn}_{0.5} \mathrm{Cd}_{0.5} \mathrm{~S} / \mathrm{RGO}$ hybrid aerogel material, it took 140 min to realize the photoreduction of $\mathrm{Cr}(\mathrm{VI})$ over $95 \%$. Such photocatalytic performance is much superior to that of other photocatalysts since only $29.2 \%, 54.8 \%, 84.1 \%$, $76.8 \%, 36.3 \%, 9.7 \%, 5.1 \%$, and $41.3 \%$ of $\mathrm{Cr}(\mathrm{VI})$ were photoreduced by $\mathrm{CdS} / \mathrm{RGO}, \mathrm{Zn}_{0.2} \mathrm{Cd}_{0.8} \mathrm{~S} / \mathrm{RGO}, \mathrm{Zn}_{0.4} \mathrm{Cd}_{0.6} \mathrm{~S} / \mathrm{RGO}$, $\mathrm{Zn}_{0.6} \mathrm{Cd}_{0.4} \mathrm{~S} / \mathrm{RGO}, \mathrm{Zn}_{0.8} \mathrm{Cd}_{0.2} \mathrm{~S} / \mathrm{RGO}, \mathrm{ZnS} / \mathrm{RGO}, \mathrm{RGO}$ aerogel, and bare $\mathrm{Zn}_{0.5} \mathrm{Cd}_{0.5} \mathrm{~S}$ solid solution after identical illumination time, respectively (Figure $7(\mathrm{a})$ ). The kinetics of photocatalytic reduction reaction of $\mathrm{Cr}(\mathrm{VI})$ were also surveyed. As plotted in Figure 7(b), linear correlation is fitted in each case, suggesting that the photoreduction process obeys a pseudofirst-order kinetic model. Therefore, the photoreduction rate constant $(k)$ can be directly determined in terms of the slopes of the fitted lines. Impressively, the photocatalytic rate for $\mathrm{Zn}_{0.5} \mathrm{Cd}_{0.5} \mathrm{~S} / \mathrm{RGO}$ aerogel $\left(k=0.098 \mathrm{~min}^{-1}\right)$ is the fastest among all the photocatalysts synthesized in this work, and their photocatalytic activities follow the increasing order of $\mathrm{ZnS} /$ RGO aerogel $<\mathrm{CdS} / \mathrm{RGO}$ aerogel $<\mathrm{Zn}_{0.8} \mathrm{Cd}_{0.2} \mathrm{~S} / \mathrm{RGO}$ aerogel $<$ bare $\mathrm{Zn}_{0.5} \mathrm{Cd}_{0.5} \mathrm{~S}$ solid solution $<\mathrm{Zn}_{0.2} \mathrm{Cd}_{0.8} \mathrm{~S} / \mathrm{RGO}$ aerogel $<\mathrm{Zn}_{0.6} \mathrm{Cd}_{0.4} \mathrm{~S} / \mathrm{RGO}$ aerogel $<\mathrm{Zn}_{0.4} \mathrm{Cd}_{0.6} \mathrm{~S} / \mathrm{RGO}$ aerogel $<\mathrm{Zn}_{0.5} \mathrm{Cd}_{0.5} \mathrm{~S} / \mathrm{RGO}$ aerogel. During the photoreduction process, the valence electrons of $\mathrm{Zn}_{x} \mathrm{Cd}_{1-x} \mathrm{~S}$ solid solution were excited to the conduction band by absorbing visible light and electron-hole pairs were generated $[49,50]$. As a consequence, $\mathrm{Cr}(\mathrm{VI})$ could be reduced to $\mathrm{Cr}(\mathrm{III})$ by capturing the photoexcited electrons; in parallel, the holes on the valence band were also reactive enough so that they could oxidize water molecules to oxygen $[49,50]$. When RGO is composited with $\mathrm{Zn}_{x} \mathrm{Cd}_{1-x} \mathrm{~S}$ solid solution, 


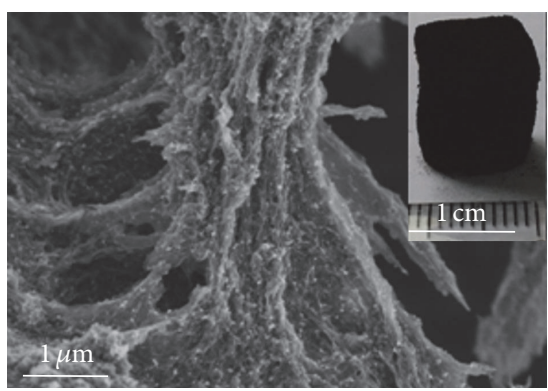

(a)

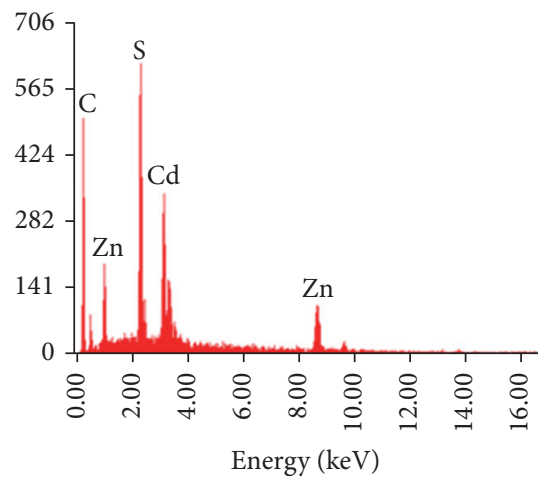

(d)

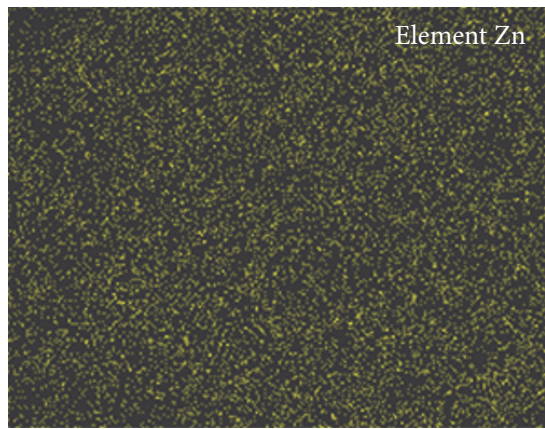

(g)

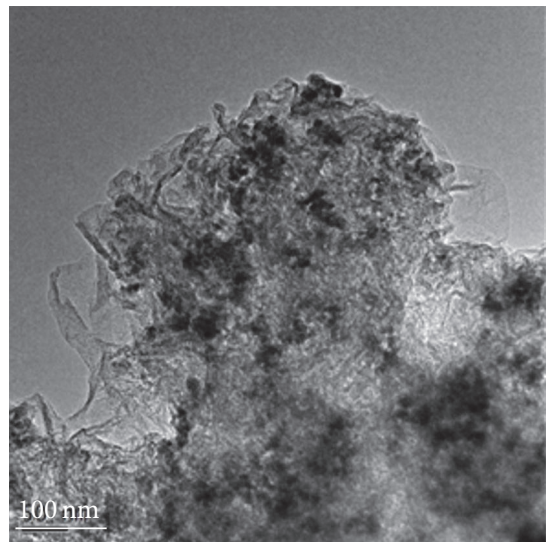

(j)

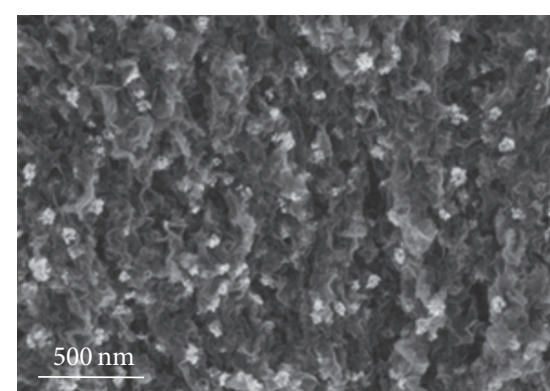

(b)

\begin{tabular}{lcc}
\hline Element & Wt\% & At\% \\
\hline CK & 49.03 & 82.87 \\
SK & 13.20 & 08.36 \\
CdL & 22.75 & 04.11 \\
ZnK & 15.02 & 04.66 \\
Matrix & Correction & ZAF \\
\hline
\end{tabular}

(e)

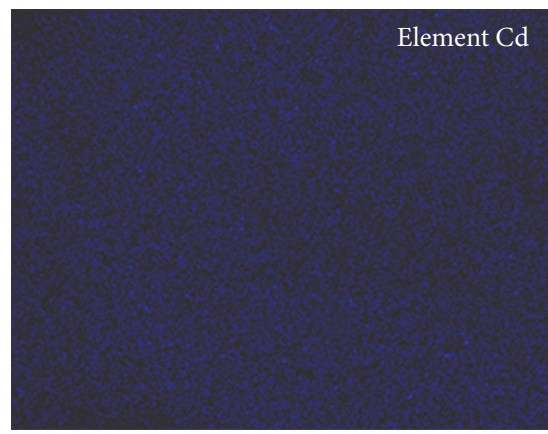

(h)

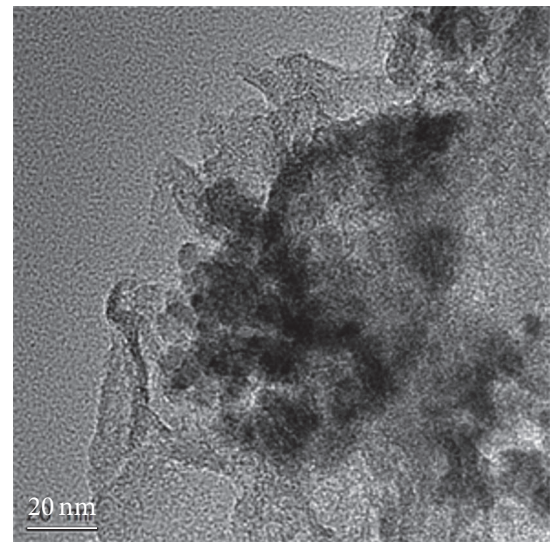

(k)

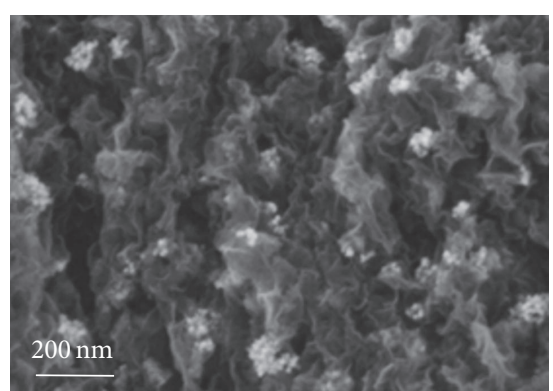

(c)

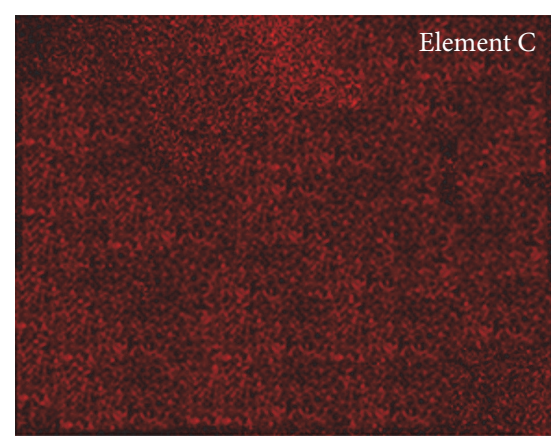

(f)

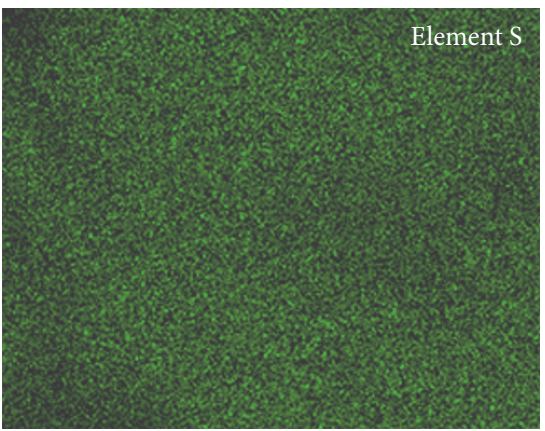

(i)

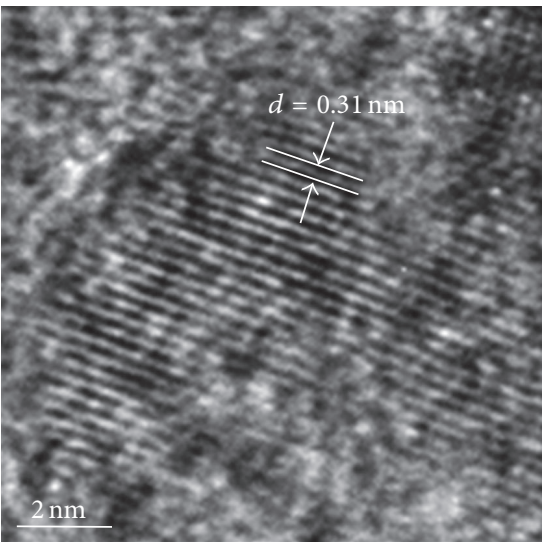

(l)

FIGURE 5: (a-c) SEM images of $\mathrm{Zn}_{0.5} \mathrm{Cd}_{0.5}$ S/RGO aerogel at different magnifications; the inset in (a) is the digital photograph of a monolithic $\mathrm{Zn}_{0.5} \mathrm{Cd}_{0.5} \mathrm{~S} / \mathrm{RGO}$ aerogel. (d) EDS spectrum of $\mathrm{Zn}_{0.5} \mathrm{Cd}_{0.5} \mathrm{~S} / \mathrm{RGO}$ aerogel. (e) The result of elemental contents of $\mathrm{C}$, Zn, Cd, and $\mathrm{S}$ contained in $\mathrm{Zn}_{0.5} \mathrm{Cd}_{0.5} \mathrm{~S} / \mathrm{RGO}$ aerogel, which was obtained from the EDS spectrum shown in (d). (f-i) EDS elemental mapping images of $\mathrm{C}$, $\mathrm{Zn}, \mathrm{Cd}$, and $\mathrm{S}$ within $\mathrm{Zn}_{0.5} \mathrm{Cd}_{0.5} \mathrm{~S} / \mathrm{RGO}$ aerogel, suggesting their uniform distribution in the sample. ( $\mathrm{j}$ and $\mathrm{k}$ ) TEM images of $\mathrm{Zn}_{0.5} \mathrm{Cd}_{0.5} \mathrm{~S} / \mathrm{RGO}$ aerogel at low and high magnifications, respectively. (l) HRTEM image of an individual $\mathrm{Zn}_{0.5} \mathrm{Cd}_{0.5} \mathrm{~S}$ solid solution nanocrystal trapped in the matrix of $\mathrm{Zn}_{0.5} \mathrm{Cd}_{0.5} \mathrm{~S} / \mathrm{RGO}$ hybrid aerogel, showing its (111) lattice plane. 


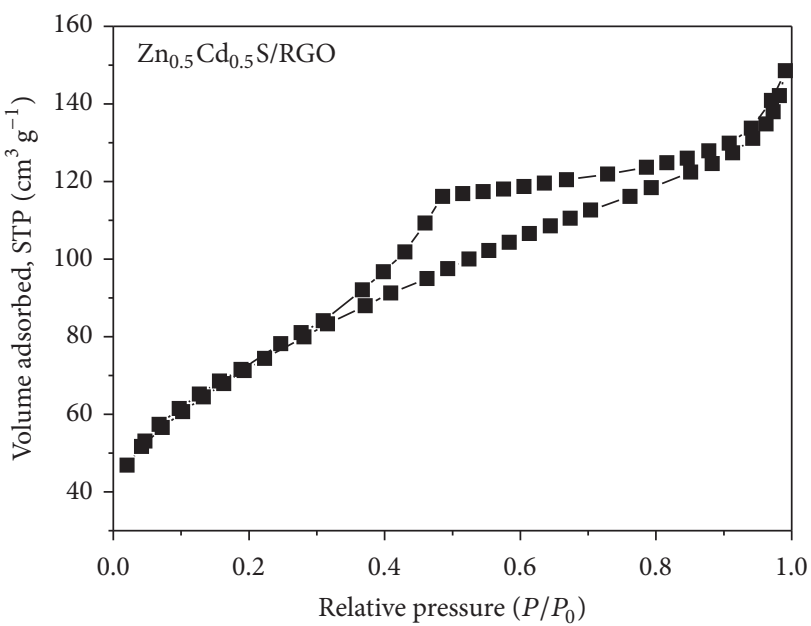

(a)

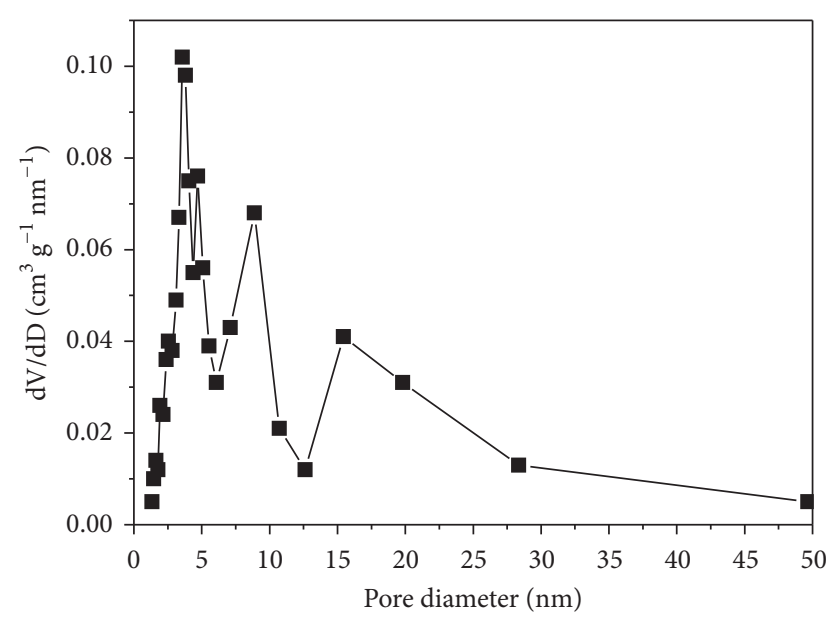

(b)

FIGURE 6: (a) Nitrogen adsorption-desorption isotherms and (b) pore size distribution of $\mathrm{Zn}_{0.5} \mathrm{Cd}_{0.5} \mathrm{~S} / \mathrm{RGO}$ hybrid aerogel.

due to rather more negative conduction band potential of $\mathrm{Zn}_{x} \mathrm{Cd}_{1-x} \mathrm{~S}$ solid solution compared with $\mathrm{RGO}$ as well as the exceptional conductivity and $\pi$-conjugation structure of RGO, the photoexcited electrons could be injected into RGO sheets, effectively promoting the electron-hole pair separation $[9,50,51]$. In this manner, RGO actually functioned as an electron collector and transporter and significantly prolonged the lifetime of charge carriers, thus speeding up the photoreduction reaction of $\operatorname{Cr}(\mathrm{VI})[9,22$, 50]. Therefore, in contrast with $\mathrm{Zn}_{0.5} \mathrm{Cd}_{0.5} \mathrm{~S}$ solid solution, the catalytic synergistic effect between $\mathrm{Zn}_{0.5} \mathrm{Cd}_{0.5} \mathrm{~S}$ and $\mathrm{RGO}$ as well as the unique hierarchically porous structure with enhanced specific surface area should be responsible for the stronger photocatalytic performance of $\mathrm{Zn}_{0.5} \mathrm{Cd}_{0.5} \mathrm{~S} / \mathrm{RGO}$ hybrid aerogel material. In previous reports, $\mathrm{Zn}_{x} \mathrm{Cd}_{1-x} \mathrm{~S}$ solid solution was hybridized with carbon nanotubes (CNTs), $\mathrm{TiO}_{2}$, and $\mathrm{CuS}$ to form $\mathrm{Zn}_{x} \mathrm{Cd}_{1-x} \mathrm{~S} / \mathrm{CNTs}, \mathrm{Zn}_{x} \mathrm{Cd}_{1-x} \mathrm{~S} / \mathrm{TiO}_{2}$, and $\mathrm{Zn}_{x} \mathrm{Cd}_{1-x} \mathrm{~S} / \mathrm{CuS}$ composites, respectively, which were utilized as visible-light-driven photocatalysts for photocatalytic applications $[17,18,52]$. Their photocatalytic activities varied as the $x$ value changed as well and depended on the band energy, the adsorption ability for visible light, the rate of interfacial charge transfer, and the separation efficiency of electron-hole pairs $[17,18,52]$. Accordingly, it is assumed that when $x$ value is equal to $0.5, \mathrm{Zn}_{0.5} \mathrm{Cd}_{0.5} \mathrm{~S} / \mathrm{RGO}$ aerogel could optimally balance these factors, resulting in the best photocatalytic performance among all the $\mathrm{Zn}_{x} \mathrm{Cd}_{1-x} \mathrm{~S} / \mathrm{RGO}$ aerogel materials.

To obtain the information about the stability and recyclability of $\mathrm{Zn}_{0.5} \mathrm{Cd}_{0.5} \mathrm{~S} / \mathrm{RGO}$ hybrid aerogel material, repetitive photoreduction of $\mathrm{Cr}(\mathrm{VI})$ under visible light illumination was carried out, and the results were presented in Figure $7(\mathrm{c})$. The photocatalytic activity is appreciably retained after successively using this photocatalyst for several times, because the percentage of photoreduced $\mathrm{Cr}(\mathrm{VI})$ is still as high as
$88.4 \%$ for the fifth visible-light-driven photocatalytic reaction. Notably, the phase, structure, and morphology of recycled $\mathrm{Zn}_{0.5} \mathrm{Cd}_{0.5} \mathrm{~S} / \mathrm{RGO}$ hybrid aerogel material remain intact and it maintains the porous architecture with $\mathrm{Zn}_{0.5} \mathrm{Cd}_{0.5} \mathrm{~S}$ solid solution firmly trapped in the RGO backbone as before (Figures S2 and S3), indicating its excellent durability and robustness. Furthermore, after consecutive photoreduction, we examined the aqueous solution of reaction mixture via atomic adsorption spectroscopy to detect the potential release of toxic $\mathrm{Cd}$ ions from photocatalyst. However, no noticeable signal of $\mathrm{Cd}$ ions is available, implying that $\mathrm{Zn}_{0.5} \mathrm{Cd}_{0.5} \mathrm{~S} / \mathrm{RGO}$ hybrid aerogel material is stable and environmentally friendly enough and hardly causes the secondary water pollution.

\section{Conclusions}

In summary, a group of $3 \mathrm{D} \mathrm{Zn}_{x} \mathrm{Cd}_{1-x} \mathrm{~S} / \mathrm{RGO}$ hydrogels with different $x$ values were prepared through a facile one-pot hydrothermal process, which was converted into self-supporting monolithic aerogels after freeze-drying. It was found that $\mathrm{Zn}_{0.5} \mathrm{Cd}_{0.5} \mathrm{~S} / \mathrm{RGO}$ hybrid aerogel had hierarchically porous network with $\mathrm{Zn}_{0.5} \mathrm{Cd}_{0.5} \mathrm{~S}$ solid solution nanoparticles well distributed in the RGO matrix. Thanks to the large specific surface area and the preferable synergetic catalytic effect between $\mathrm{Zn}_{0.5} \mathrm{Cd}_{0.5} \mathrm{~S}$ solid solution and $\mathrm{RGO}, \mathrm{Zn}_{0.5} \mathrm{Cd}_{0.5} \mathrm{~S} / \mathrm{RGO}$ hybrid aerogel material exhibited the strongest visible-light-driven photocatalytic activity toward the photoreduction of $\mathrm{Cr}(\mathrm{VI})$ as compared with other $\mathrm{Zn}_{x} \mathrm{Cd}_{1-x} \mathrm{~S} / \mathrm{RGO}$ aerogel materials $(x \neq 0.5)$ and bare $\mathrm{Zn}_{0.5} \mathrm{Cd}_{0.5} \mathrm{~S}$ solid solution. Besides, $\mathrm{Zn}_{0.5} \mathrm{Cd}_{0.5} \mathrm{~S} / \mathrm{RGO}$ hybrid aerogel material featured satisfactory photocatalytic stability and recyclability. Relying on the convenience and versatility of the present methodology, it should be facile to fulfill the incorporation of other active or functional species with different constituents and shapes into RGO framework to 

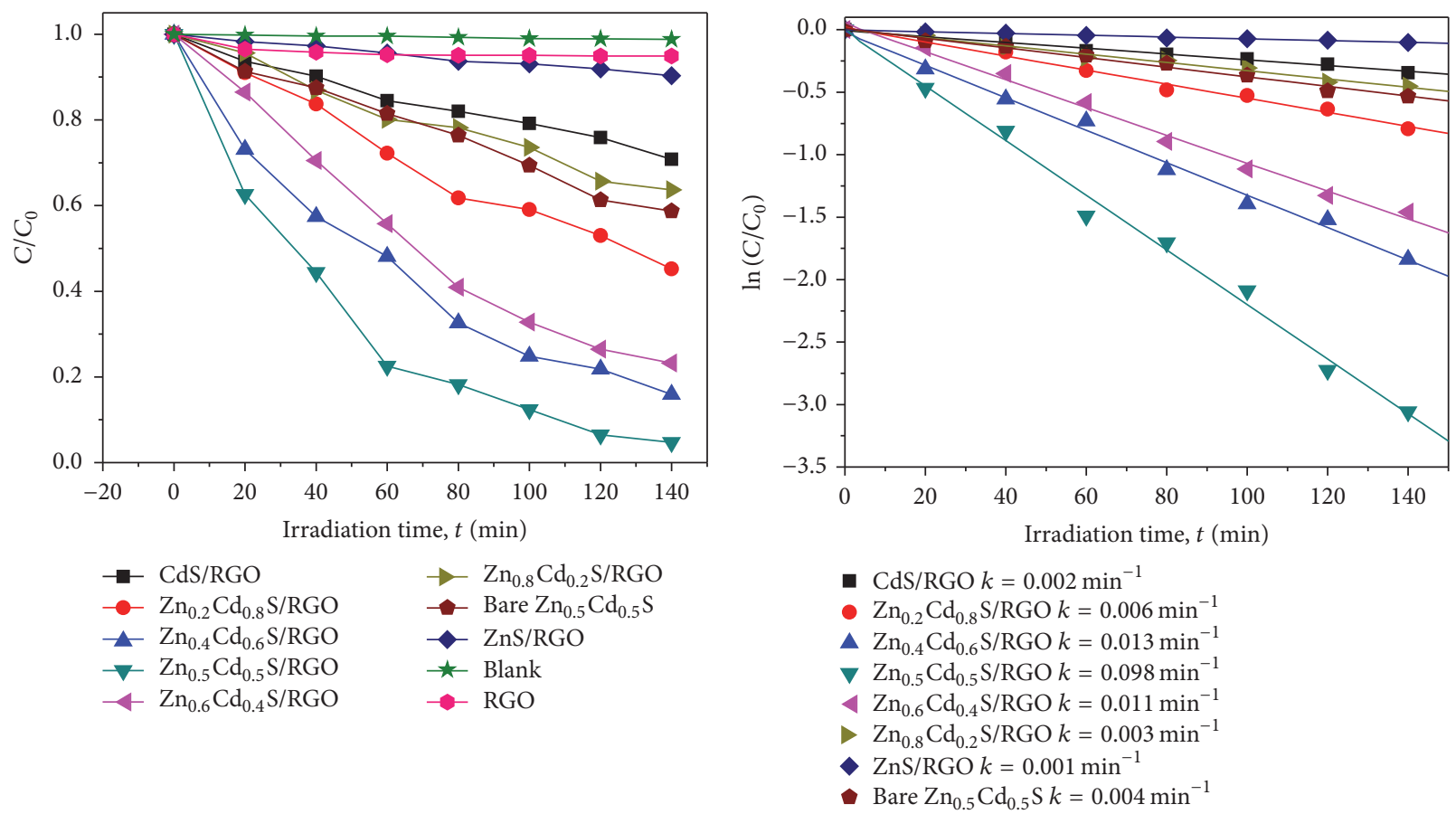

(a)
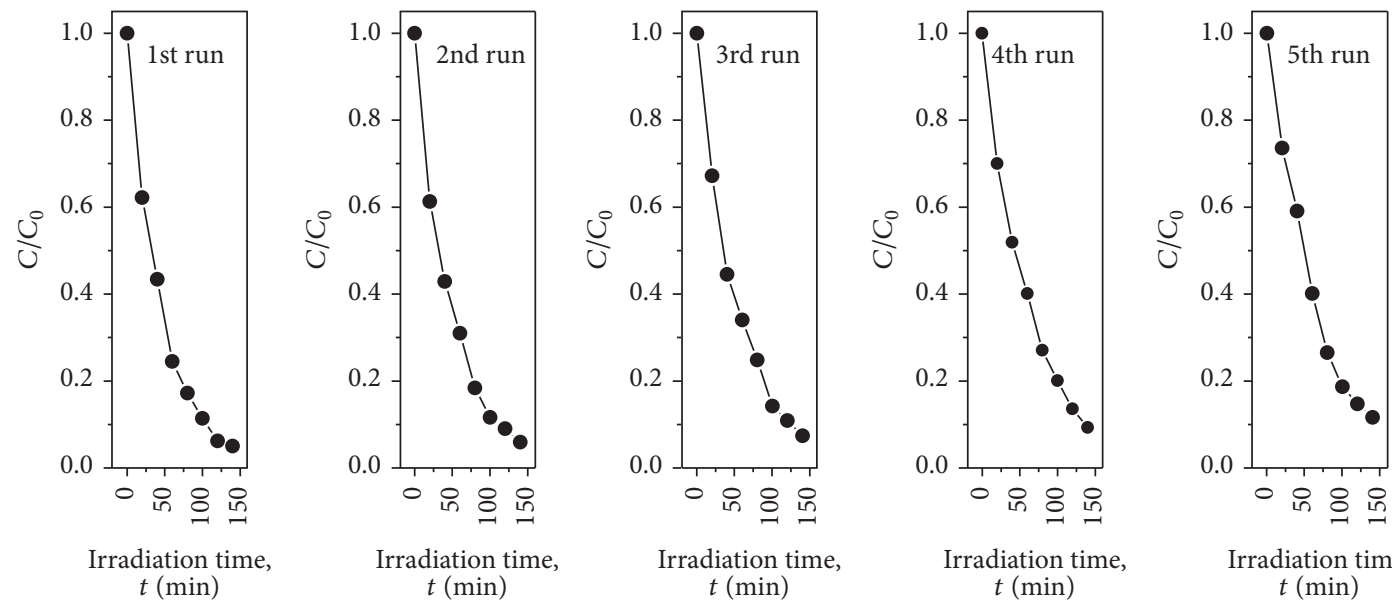

(c)

Irradiation time, $t(\min )$

Irradiation time,

FIGURE 7: (a) Performances of photoreduction of $\mathrm{Cr}(\mathrm{VI})$ under visible light catalyzed by $\mathrm{Zn}_{x} \mathrm{Cd}_{1-x}$ S/RGO hybrid aerogels, RGO aerogel, and bare $\mathrm{Zn}_{0.5} \mathrm{Cd}_{0.5} \mathrm{~S}$ solid solution as well as the performance of photoreduction of $\mathrm{Cr}(\mathrm{VI})$ under visible light in the absence of any photocatalyst. (b) Kinetic curves of the visible-light-driven photocatalytic reduction reactions of $\mathrm{Cr}(\mathrm{VI})$ catalyzed by the currently developed photocatalysts.

(c) Recycling experiments of photocatalytic reduction of $\mathrm{Cr}(\mathrm{VI})$ over $\mathrm{Zn}_{0.5} \mathrm{Cd}_{0.5} \mathrm{~S} / \mathrm{RGO}$ hybrid aerogel material.

construct more RGO-based aerogel materials with distinct microscopic morphologies, high specific surface area, and reinforced properties, which would find applications in lots of important fields such as catalysis, energy storage, and environmental protection.

\section{Competing Interests}

The authors declare that there is no conflict of interests regarding the publication of this paper.

\section{Acknowledgments}

This work was supported by the National Natural Science Foundation of China (21401015, 21403020, and 21101136), the Basic and Frontier Research Program of Chongqing Municipality (cstc2014jcyjA50012, cstc2015jcyjA90020, and cstc2016jcyjA0137), the Scientific and Technological Research Program of Chongqing Municipal Education Commission (KJ1501104, KJ1501101, and KJ1501126), the Natural Science Foundation of Yongchuan (Ycstc, 2014nc4001), and the 
Foundation of Chongqing University of Arts and Sciences (R2013CJ04 and R2012CJ15).

\section{References}

[1] M. V. Dozzi, A. Saccomanni, and E. Selli, "Cr(VI) photocatalytic reduction: effects of simultaneous organics oxidation and of gold nanoparticles photodeposition on $\mathrm{TiO}_{2}$," Journal of Hazardous Materials, vol. 211-212, pp. 188-195, 2012.

[2] Y. Yang, G. Wang, Q. Deng et al., "Enhanced photocatalytic activity of hierarchical structure $\mathrm{TiO}_{2}$ hollow spheres with reactive (001) facets for the removal of toxic heavy metal Cr(VI)," RSC Advances, vol. 4, no. 65, pp. 34577-34583, 2014.

[3] R. Güell, E. Anticó, V. Salvadó, and C. Fontàs, "Efficient hollow fiber supported liquid membrane system for the removal and preconcentration of $\mathrm{Cr}(\mathrm{VI})$ at trace levels," Separation and Purification Technology, vol. 62, no. 2, pp. 389-393, 2008.

[4] S. Mor, K. Ravindra, and N. R. Bishnoi, "Adsorption of chromium from aqueous solution by activated alumina and activated charcoal," Bioresource Technology, vol. 98, no. 4, pp. 954-957, 2007.

[5] Y. Xing, X. Chen, and D. Wang, "Electrically regenerated ion exchange for removal and recovery of $\mathrm{Cr}(\mathrm{VI})$ from wastewater," Environmental Science and Technology, vol. 41, no. 4, pp. 14391443, 2007.

[6] J.-W. Fan, X.-H. Liu, and J. Zhang, "The synthesis of $\mathrm{TiO}_{2}$ and $\mathrm{TiO}_{2}-\mathrm{Pt}$ and their application in the removal of $\mathrm{Cr}(\mathrm{VI})$," Environmental Technology, vol. 32, no. 4, pp. 427-437, 2011.

[7] M. Shirzad-Siboni, M. Farrokhi, R. Darvishi Cheshmeh Soltani, A. Khataee, and S. Tajassosi, "Photocatalytic reduction of hexavalent chromium over $\mathrm{ZnO}$ nanorods immobilized on kaolin," Industrial and Engineering Chemistry Research, vol. 53, no. 3, pp. 1079-1087, 2014.

[8] S. Liu, M.-Q. Yang, and Y.-J. Xu, "Surface charge promotes the synthesis of large, flat structured graphene-(CdS nanowire)$\mathrm{TiO}_{2}$ nanocomposites as versatile visible light photocatalysts," Journal of Materials Chemistry A, vol. 2, no. 2, pp. 430-440, 2014.

[9] X. Wang, H. Tian, X. Cui, W. Zheng, and Y. Liu, "Onepot hydrothermal synthesis of mesoporous $\mathrm{Zn}_{\mathrm{x}} \mathrm{Cd}_{1-\mathrm{x}} \mathrm{S} /$ reduced graphene oxide hybrid material and its enhanced photocatalytic activity," Dalton Transactions, vol. 43, no. 34, pp. 12894-12903, 2014.

[10] W. Li, D. Li, Z. Chen et al., "High-efficient degradation of dyes by $\mathrm{Zn}_{x} \mathrm{Cd}_{1-x} \mathrm{~S}$ solid solutions under visible light irradiation," The Journal of Physical Chemistry C, vol. 112, no. 38, pp. 14943-14947, 2008.

[11] W. Wang, W. Zhu, and H. Xu, "Monodisperse, mesoporous $\mathrm{Zn}_{x} \mathrm{Cd}_{1-x} \mathrm{~S}$ nanoparticles as stable visible-light-driven photocatalysts," The Journal of Physical Chemistry C, vol. 112, no. 43, pp. 16754-16758, 2008.

[12] M. Sun, T. Yan, Q. Yan et al., "Novel visible-light driven $g$ $\mathrm{C}_{3} \mathrm{~N}_{4} / \mathrm{Zn}_{0.25} \mathrm{Cd}_{0.75} \mathrm{~S}$ composite photocatalyst for efficient degradation of dyes and reduction of $\mathrm{Cr}(\mathrm{VI})$ in water," RSC Advances, vol. 4, no. 38, pp. 19980-19986, 2014.

[13] A. Ma, Z. Tang, S. Shen, L. Zhi, and J. Yang, "Controlled synthesis of $\mathrm{Zn}_{x} \mathrm{Cd}_{1-x} \mathrm{~S}$ nanorods and their composite with RGO for high-performance visible-light photocatalysis," RSC Advances, vol. 5, no. 35, pp. 27829-27836, 2015.

[14] J. Yan, K. Wang, Q. Liu et al., "One-pot synthesis of $\mathrm{Cd}_{x} \mathrm{Zn}_{1-x} \mathrm{~S}-$ reduced graphene oxide nanocomposites with improved photoelectrochemical performance for selective determination of $\mathrm{Cu}^{2+}$, , RSC Advances, vol. 3, no. 34, pp. 14451-14457, 2013.
[15] X. Xu, R. Lu, X. Zhao, Y. Zhu, S. Xu, and F. Zhang, "Novel mesoporous $\mathrm{Zn}_{x} \mathrm{Cd}_{1-x} \mathrm{~S}$ nanoparticles as highly efficient photocatalysts," Applied Catalysis B: Environmental, vol. 125, pp. 11-20, 2012.

[16] J. Zhong, Y. Zhang, C. Hu et al., "Supercritical solvothermal preparation of $\mathrm{Zn}_{\mathrm{x}} \mathrm{Cd}_{1-\mathrm{x}} \mathrm{S}$ visible photocatalyst with enhanced activity," Journal of Materials Chemistry A, vol. 2, no. 46, pp. 19641-19647, 2014.

[17] L. Wang, Z. Yao, F. Jia, B. Chen, and Z. Jiang, "A facile synthesis of $\mathrm{Zn}_{\mathrm{x}} \mathrm{Cd}_{1-\mathrm{x}} \mathrm{S} / \mathrm{CNT}$ nanocomposite photocatalyst for $\mathrm{H}_{2}$ production," Dalton Transactions, vol. 42, no. 27, pp. 99769981, 2013.

[18] W. Li, D. Li, S. Meng, W. Chen, X. Fu, and Y. Shao, "Novel approach to enhance photosensitized degradation of rhodamine $\mathrm{B}$ under visible light irradiation by the $\mathrm{Zn}_{x} \mathrm{Cd}_{1-x} \mathrm{~S} / \mathrm{TiO}_{2}$ nanocomposites," Environmental Science and Technology, vol. 45, no. 7, pp. 2987-2993, 2011.

[19] S. Lou, Y. Wang, S. Zhou et al., "A facile method to immobilize $\mathrm{Zn}_{\mathrm{x}} \mathrm{Cd}_{1-\mathrm{x}} \mathrm{S}$ nanocrystals on graphene nanoribbons," Materials Letters, vol. 67, no. 1, pp. 169-172, 2012.

[20] D. A. Reddy, J. Choi, S. Lee, R. Ma, and T. K. Kim, "Selfassembled macro porous $\mathrm{ZnS}$-graphene aerogels for photocatalytic degradation of contaminants in water," RSC Advances, vol. 5, no. 24, pp. 18342-18351, 2015.

[21] W. Xiao, Y. Zhang, L. Tian, H. Liu, B. Liu, and Y. Pu, "Facile synthesis of reduced graphene oxide/titania composite hollow microspheres based on sonication-assisted interfacial selfassembly of tiny graphene oxide sheets and the photocatalytic property," Journal of Alloys and Compounds, vol. 665, pp. 21-30, 2016.

[22] W. Xiao, Y. Zhang, and B. Liu, "Raspberrylike $\mathrm{SiO}_{2} @$ reduced graphene oxide@AgNP composite microspheres with high aqueous dispersity and excellent catalytic activity," ACS Applied Materials and Interfaces, vol. 7, no. 11, pp. 6041-6046, 2015.

[23] P. Wang, J. Wang, X. Wang et al., "One-step synthesis of easy-recycling $\mathrm{TiO}_{2}$-rGO nanocomposite photocatalysts with enhanced photocatalytic activity," Applied Catalysis B: Environmental, vol. 132-133, pp. 452-459, 2013.

[24] S. Zargari, R. Rahimi, A. Ghaffarinejad, and A. Morsali, "Enhanced visible light photocurrent response and photodegradation efficiency over $\mathrm{TiO}_{2}$-graphene nanocomposite pillared with tin porphyrin," Journal of Colloid and Interface Science, vol. 466, pp. 310-321, 2016.

[25] R. Rahimi, S. Zargari, A. Yousefi, M. Yaghoubi Berijani, A. Ghaffarinejad, and A. Morsali, "Visible light photocatalytic disinfection of $E$. coli with $\mathrm{TiO}_{2}$-graphene nanocomposite sensitized with tetrakis(4-carboxyphenyl)porphyrin," Applied Surface Science, vol. 355, pp. 1098-1106, 2015.

[26] R. Wang, C. Xu, J. Sun, L. Gao, and H. Yao, "Solvothermalinduced 3D macroscopic $\mathrm{SnO}_{2} /$ nitrogen-doped graphene aerogels for high capacity and long-life lithium storage," ACS Applied Materials and Interfaces, vol. 6, no. 5, pp. 3427-3436, 2014.

[27] Z. Zhang, F. Xiao, Y. Guo, S. Wang, and Y. Liu, "One-pot selfassembled three-dimensional $\mathrm{TiO}_{2}$-graphene hydrogel with improved adsorption capacities and photocatalytic and electrochemical activities," ACS Applied Materials and Interfaces, vol. 5, no. 6, pp. 2227-2233, 2013.

[28] B. Adhikari, A. Biswas, and A. Banerjee, "Graphene oxidebased hydrogels to make metal nanoparticle-containing reduced graphene oxide-based functional hybrid hydrogels," ACS Applied Materials and Interfaces, vol. 4, no. 10, pp. 5472-5482, 2012. 
[29] J. Li, C.-Y. Liu, and Y. Liu, "Au/graphene hydrogel: synthesis, characterization and its use for catalytic reduction of 4nitrophenol," Journal of Materials Chemistry, vol. 22, no. 17, pp. 8426-8430, 2012.

[30] Z. Fan, B. Liu, J. Wang et al., "A novel wound dressing based on Ag/graphene polymer hydrogel: effectively kill bacteria and accelerate wound healing," Advanced Functional Materials, vol. 24, no. 25, pp. 3933-3943, 2014.

[31] X. Wang, C. Li, and G. Shi, "A high-performance platinum electrocatalyst loaded on a graphene hydrogel for high-rate methanol oxidation," Physical Chemistry Chemical Physics, vol. 16, no. 21, pp. 10142-10148, 2014.

[32] C. Hu, H. Cheng, Y. Zhao et al., "Newly-designed complex ternary $\mathrm{Pt} / \mathrm{PdCu}$ nanoboxes anchored on three-dimensional graphene framework for highly efficient ethanol oxidation," Advanced Materials, vol. 24, no. 40, pp. 5493-5498, 2012.

[33] L. Ren, K. S. Hui, and K. N. Hui, "Self-assembled free-standing three-dimensional nickel nanoparticle/graphene aerogel for direct ethanol fuel cells," Journal of Materials Chemistry A, vol. 1, no. 18, pp. 5689-5694, 2013.

[34] W. Chen, S. Li, C. Chen, and L. Yan, "Self-assembly and embedding of nanoparticles by in situ reduced graphene for preparation of a 3D graphene/nanoparticle aerogel," Advanced Materials, vol. 23, no. 47, pp. 5679-5683, 2011.

[35] H. Yin, S. Zhao, J. Wan et al., “Three-dimensional graphene/ metal oxide nanoparticle hybrids for high-performance capacitive deionization of saline water," Advanced Materials, vol. 25, no. 43, pp. 6270-6276, 2013.

[36] S. Wu, W. Chen, and L. Yan, "Fabrication of a 3D $\mathrm{MnO}_{2}$ /graphene hydrogel for high-performance asymmetric supercapacitors," Journal of Materials Chemistry A, vol. 2, no. 8, pp. 2765-2772, 2014.

[37] J. Yuan, J. Zhu, H. Bi et al., "Graphene-based 3D composite hydrogel by anchoring $\mathrm{Co}_{3} \mathrm{O}_{4}$ nanoparticles with enhanced electrochemical properties," Physical Chemistry Chemical Physics, vol. 15, no. 31, pp. 12940-12945, 2013.

[38] H. Wang, H. Yi, X. Chen, and X. Wang, “One-step strategy to three-dimensional graphene/ $\mathrm{VO}_{2}$ nanobelt composite hydrogels for high performance supercapacitors," Journal of Materials Chemistry A, vol. 2, no. 4, pp. 1165-1173, 2014.

[39] S. Xu, Z. Lei, and P. Wu, "Facile preparation of 3D $\mathrm{MoS}_{2} / \mathrm{MoSe}_{2}$ nanosheet-graphene networks as efficient electrocatalysts for the hydrogen evolution reaction," Journal of Materials Chemistry A, vol. 3, no. 31, pp. 16337-16347, 2015.

[40] F. Fu, Y. Chen, P. Li et al., "Three-dimensional $\mathrm{CoS}_{2} / \mathrm{RGO}$ hierarchical architecture as superior-capability anode for lithium ion batteries," RSC Advances, vol. 5, no. 88, pp. 71790-71795, 2015.

[41] F. Cai, R. Sun, Y. Kang, H. Chen, M. Chen, and Q. Li, “One-step strategy to a three-dimensional NiS-reduced graphene oxide hybrid nanostructure for high performance supercapacitors," RSC Advances, vol. 5, no. 29, pp. 23073-23079, 2015.

[42] Y. Chen, S. Li, L. Huang, and D. Pan, "Single-step direct fabrication of luminescent $\mathrm{Cu}$-doped $\mathrm{Zn}_{\mathrm{x}} \mathrm{Cd}_{1-\mathrm{x}} \mathrm{S}$ quantum dot thin films via a molecular precursor solution approach and their application in luminescent, transparent, and conductive thin films," Nanoscale, vol. 6, no. 16, pp. 9640-9645, 2014.

[43] W. Han, L. Ren, L. Gong et al., "Self-assembled threedimensional graphene-based aerogel with embedded multifarious functional nanoparticles and its excellent photoelectrochemical activities," ACS Sustainable Chemistry and Engineering, vol. 2, no. 4, pp. 741-748, 2014.
[44] K. Subramani, D. Jeyakumar, and M. Sathish, "Manganese hexacyanoferrate derived $\mathrm{Mn}_{3} \mathrm{O}_{4}$ nanocubes-reduced graphene oxide nanocomposites and their charge storage characteristics in supercapacitors," Physical Chemistry Chemical Physics, vol.16, no. 10, pp. 4952-4961, 2014.

[45] J. Ye, L. Ma, W. Chen et al., "Supramolecule-mediated synthesis of $\mathrm{MoS}_{2}$ /reduced graphene oxide composites with enhanced electrochemical performance for reversible lithium storage," Journal of Materials Chemistry A, vol. 3, no. 13, pp. 6884-6893, 2015.

[46] X. Wu, J. Liu, Z. Chen et al., "Amino acid assisted synthesis of mesoporous $\mathrm{TiO}_{2}$ nanocrystals for high performance dyesensitized solar cells," Journal of Materials Chemistry, vol. 22, no. 21, pp. 10438-10440, 2012.

[47] J. Ma, L. Yin, and T. Ge, “3D hierarchically mesoporous $\mathrm{Cu}-$ doped $\mathrm{NiO}$ nanostructures as high-performance anode materials for lithium ion batteries," CrystEngComm, vol. 17, no. 48, pp. 9336-9347, 2015.

[48] A. C. S. Sekhar, C. J. Meera, K. V. Ziyad, C. S. Gopinath, and C. P. Vinod, "Synthesis and catalytic activity of monodisperse goldmesoporous silica core-shell nanocatalysts," Catalysis Science and Technology, vol. 3, no. 5, pp. 1190-1193, 2013.

[49] Y. Du, Z. Tao, J. Guan et al., "Microwave-assisted synthesis of hematite/activated graphene composites with superior performance for photocatalytic reduction of $\mathrm{Cr}(\mathrm{VI})$, , RSC Advances, vol. 5, no. 99, pp. 81438-81444, 2015.

[50] L. Shen, L. Huang, S. Liang, R. Liang, N. Qin, and L. Wu, "Electrostatically derived self-assembly of $\mathrm{NH}_{2}$-mediated zirconium MOFs with graphene for photocatalytic reduction of $\mathrm{Cr}(\mathrm{VI})$," RSC Advances, vol. 4, no. 5, pp. 2546-2549, 2014.

[51] C. Xing, Y. Zhang, W. Yan, and L. Guo, "Band structurecontrolled solid solution of $\mathrm{Cd}_{1-x} \mathrm{Zn}_{x} \mathrm{~S}$ photocatalyst for hydrogen production by water splitting," International Journal of Hydrogen Energy, vol. 31, pp. 2018-2024, 2006.

[52] W. Zhang and R. Xu, "Surface engineered active photocatalysts without noble metals: $\mathrm{CuS}--\mathrm{Zn}_{\mathrm{x}} \mathrm{Cd}_{1-\mathrm{x}} \mathrm{S}$ nanospheres by onestep synthesis," International Journal of Hydrogen Energy, vol. 34, no. 20, pp. 8495-8503, 2009. 

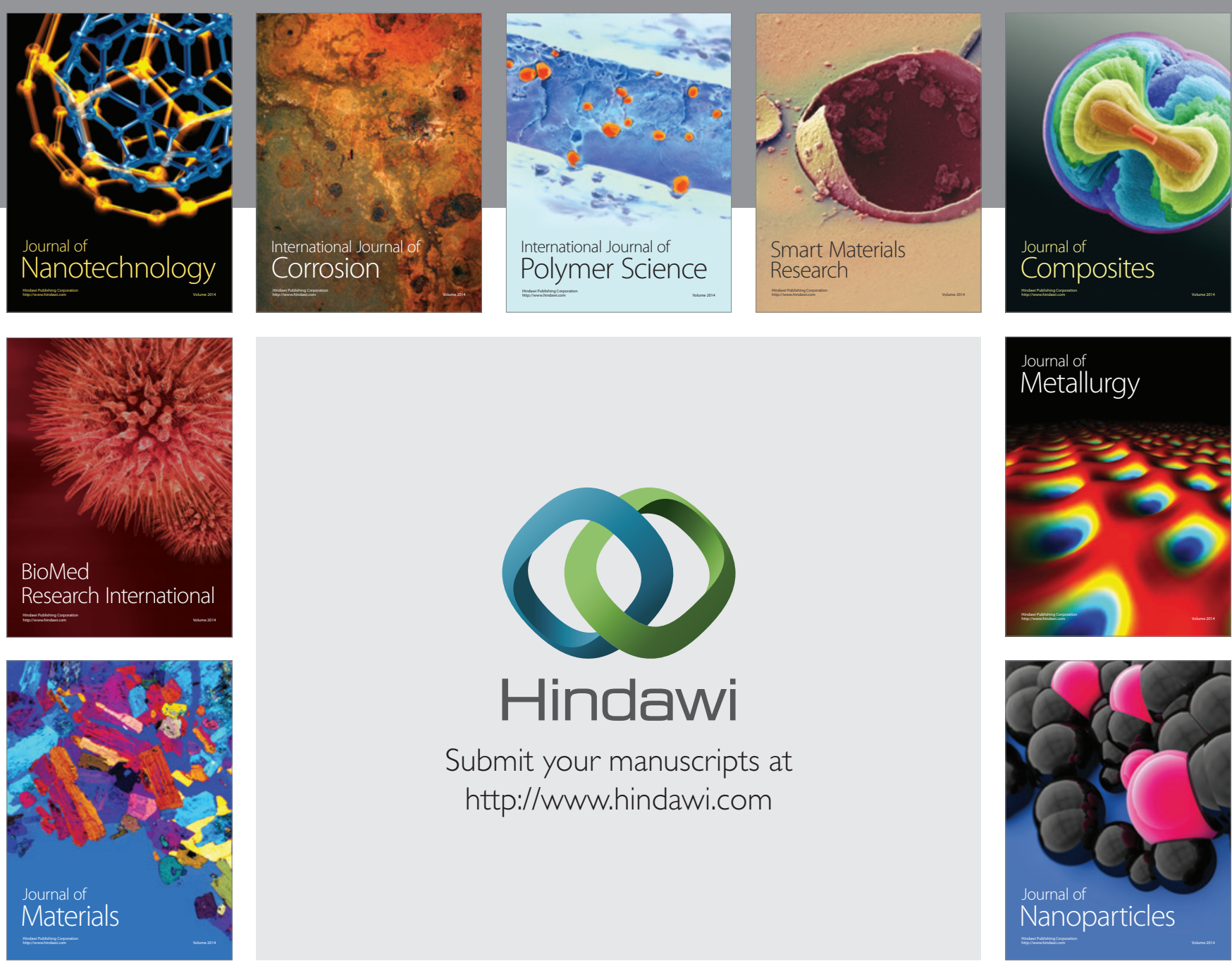

\section{Hindawi}

Submit your manuscripts at

http://www.hindawi.com

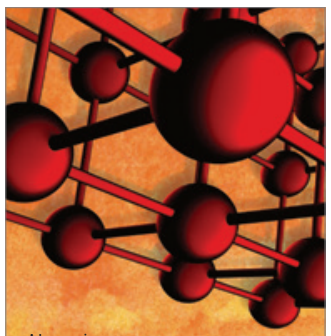

Materials Science and Engineering
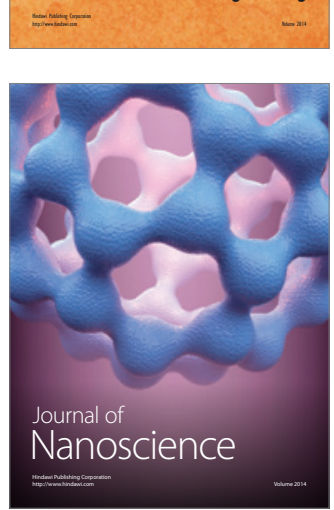
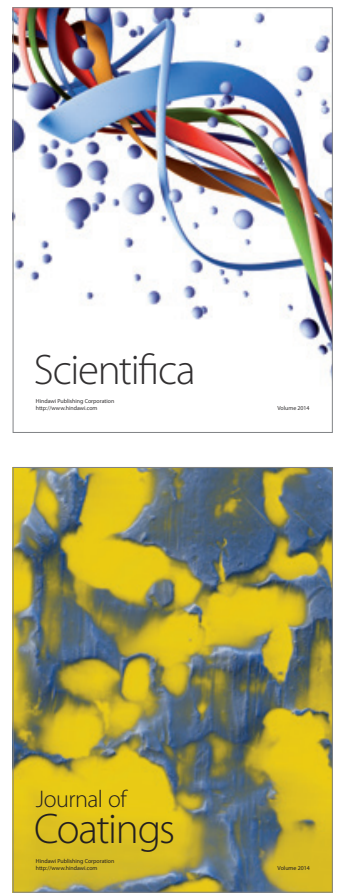
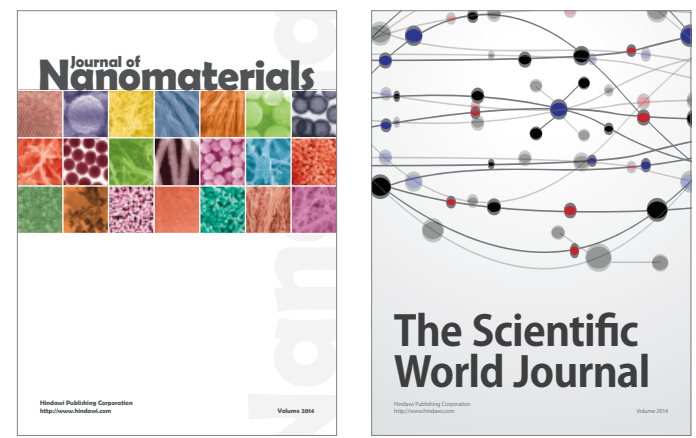

The Scientific World Journal
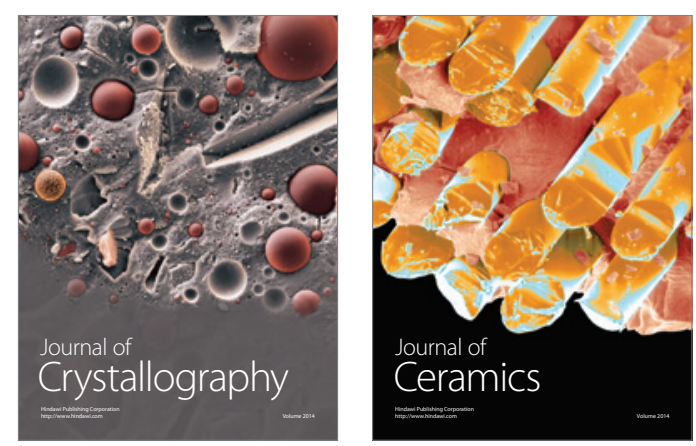
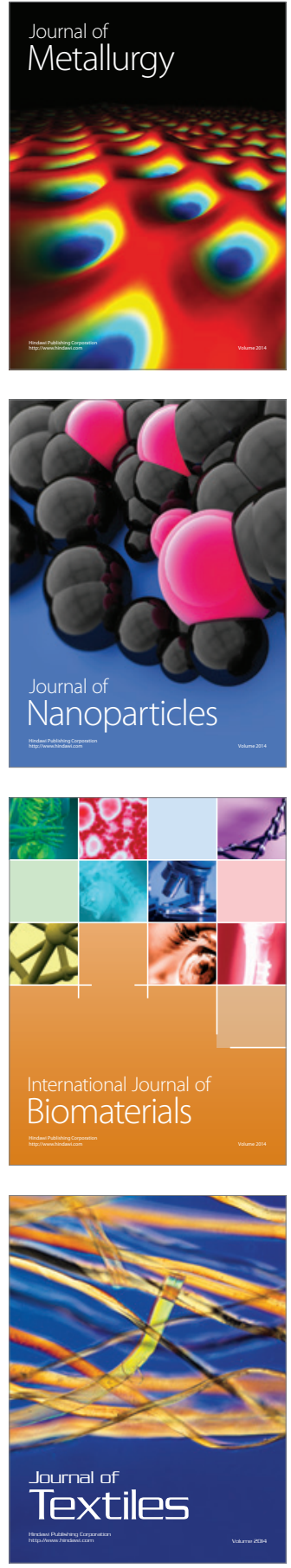